\title{
Consumption, Aggregate Wealth and Expected Stock Returns*
}

\author{
Martin Lettau
}

and

Sydney Ludvigson

Federal Reserve Bank of New York

First draft: February 26, 1999

June 8, 1999

\footnotetext{
*Address: Research Department, Federal Reserve Bank of New York, 33 Liberty St., New York, NY 10045; martin.lettau@ny.frb.org, and sydney.ludvigson@ny.frb.org. Lettau is also affiliated with the CEPR. Updated versions of this paper may be found at ww.ny.frb.org/rmaghome/economist/ludvigson.html. The authors are grateful to John Y. Campbell, Steve Cecchetti, Todd Clark, Ken French, Owen Lamont, James Stock and to seminar participants at the National Bureau of Economic Research May 1999 Asset Pricing meeting, the New York Area Macroeconomic Workshop May 1999, and the New York Federal Reserve for helpful comments, and to Jeffrey Brown and Clair Liou for research assistance. The views expressed are those of the authors and do not necessarily reflect those of the Federal Reserve Bank of New York or the Federal Reserve System. Any errors or omissions are the responsibility of the authors.
} 


\begin{abstract}
This paper studies the role of detrended wealth in predicting stock returns. We call a transitory movement in wealth one that produces a deviation from its shared trend with consumption and labor income. Using U.S. quarterly stock market data we find that these trend deviations in wealth are strong predictors of both real stock returns and excess returns over a Treasury bill rate. We also find that this variable is a better forecaster of future returns at short and intermediate horizons than is the dividend yield, the earnings yield, the dividend payout ratio and several other popular forecasting variables.

Why should wealth, detrended in this way, forecast asset returns? We show that a wide class of optimal models of consumer behavior imply that the log consumption-aggregate (human and nonhuman) wealth ratio forecasts the expected return on aggregate wealth, or the market portfolio. Although this ratio is not observable, we demonstrate that its important predictive components may be expressed in terms of observable variables, namely in terms of consumption, nonhuman wealth and labor income. The framework implies that these variables are cointegrated, and that deviations from this shared trend summarize agents' expectations of future returns on the market portfolio. (JEL G10, E21)
\end{abstract}




\section{Introduction}

Understanding the empirical linkages between macroeconomic variables and financial markets has long been a goal of financial economics. One reason for the interest in these linkages is that expected excess returns on common stocks appear to vary with the business cycle. ${ }^{1}$ This evidence suggests that stock returns should be forecastable by business cycle variables at cyclical frequencies. Indeed, the forecastability of stock returns is well documented. The studies of Shiller (1984), Flood, Hodrick and Kaplan (1986), Campbell and Shiller (1988), Fama and French (1988), Hodrick (1992) and Lamont (1998), to mention just a few, argue that financial indicators such as the ratios of price to dividends, price to earnings, or dividends to earnings have predictive power for excess returns over a Treasury-bill rate. These financial variables, however, have been most successful at predicting returns over long horizons. Over horizons spanning the length of a typical business cycle, stock returns have typically been found to be only weakly forecastable. ${ }^{2}$ Moreover, traditional macroeconomic variables have proven especially dismal as predictive variables.

The question of whether expected returns vary at cyclical frequencies and with macroeconomic variables is also pertinent to the debate over why excess returns are predictable. One possibility is that financial markets are inefficient. Alternatively, predictable variation in returns could simply reflect the rational response of agents to time-varying investment opportunities, possibly driven by cyclical variation in risk aversion (e.g., Campbell and Cochrane, 1999) or in the joint distribution of consumption and asset returns. If these rational explanations are correct, it is reasonable to expect that key macroeconomic variables should perform an important function in forecasting stock returns. As yet, however, there is little

\footnotetext{
${ }^{1}$ This conclusion is often drawn from the volatility-test literature: the procyclical volatility of pricedividend ratios cannot be accounted for by variation in expected dividends or the risk free rate, implying that expected excess returns must vary. See, for example, Campbell and Shiller (1988), Shiller (1989), Cochrane (1991a, 1991b).

${ }^{2}$ One exception to this is a study by Campbell (1987) which found that Treasury bill rates and several measures of the term spread could explain a substantial fraction of the variation in next month's excess stock return. However, these findings appear to be a feature of the sample period used in that study. Extending the sample out to the third quarter of 1998 , these indicators display much weaker forecasting power.
} 
empirical evidence that real macroeconomic variables perform such a function.

This paper adopts a new approach to investigating the linkages between macroeconomics and financial markets. We study the role of transitory movements in household wealth for predicting stock market fluctuations. We detrend wealth with aggregate consumption and aggregate labor income, measuring a transitory movement in wealth as a deviation from its shared trend with these variables. Our results show that these trend deviations in wealth are a strong univariate predictor of both raw stock returns and excess stock returns over a Treasury bill rate, and can account for a substantial fraction of the variation in future returns. This variable provides information about future stock returns that is not captured by lagged values of other popular forecasting variables, and displays its greatest predictive power for returns over business cycle frequencies, those ranging from one to five quarters. This result occurs despite the fact that the individual growth rates of consumption, labor income, and wealth-like other macroeconomic variables-bear little relationship with future stock returns.

Why should household wealth, detrended in this way, forecast asset returns? We show that this feature of the data may arise as an implication of a wide range of forward-looking models of consumer behavior where consumption is a function of aggregate wealth (the "market" portfolio), defined as the sum of human and nonhuman wealth. To make the framework tractable, we employ a log-linear approximation of the intertemporal budget constraint. For a wide class of preferences, the log consumption-aggregate wealth ratio predicts asset returns because it is a function of expected future returns on the market portfolio. This result has been noted previously by Campbell and Mankiw (1989) and is the starting point of our theoretical framework.

There are two important obstacles that must be overcome before the log consumptionaggregate wealth ratio can be empirically linked with future asset returns. The most immediate is that aggregate wealth - specifically the human capital component of it - is unobservable. One way to make it observable would be to find a proxy for human capital. This approach is likely to be fraught with practical obstacles, however, since there is little direct evidence available to assess the empirical validity of such a proxy. Instead, this paper argues that the important predictive components of the consumption-aggregate wealth ratio 
for future market returns may be expressed in terms of observable variables, namely in terms of consumption, nonhuman wealth and current labor income.

Our approach assumes that aggregate labor income may be well described by the product of a stationary "return", times the aggregate stock of human capital, implying that the nonstationary component of human capital may be captured by labor income itself. Put another way, labor income is just the annuity value of human wealth. This specification for labor income is quite general: it places no restrictions on the functional form of expected or realized returns to human capital, and it makes no assumptions about the relationship between returns to human capital and returns to nonhuman capital, or assets. It follows that the unobservable log consumption-aggregate wealth ratio may be expressed as the difference between log consumption and a weighted average of log labor income and log asset wealth. The weights on log labor income and log assets are just the average ratios of human and nonhuman wealth in aggregate wealth, respectively.

The model we investigate implies that the log of consumption, labor income and nonhuman wealth share a common stochastic trend (they are cointegrated), and that the parameters of this shared trend are the average shares of human and nonhuman wealth in aggregate wealth. But it is the stationary deviations from this shared trend, which produce movements in the consumption-aggregate wealth ratio that are important for future asset returns. This follows from the fact that the consumption-aggregate wealth ratio summarizes agents' expectations of future returns on the market portfolio. Accordingly, these deviations from trend may forecast returns to nonhuman wealth, as long as the expected return to human capital is not too volatile.

A remaining obstacle to using deviations in the common trend among consumption, labor income and asset wealth as a forecasting variable is that the parameters of this shared trend are unobservable, and must therefore be estimated. In ordinary empirical applications this estimation is problematic due to the presence of endogenous regressors. In our application, however, consumption, labor income and asset wealth are cointegrated and we may obtain a "superconsistent" estimate of the cointegrating parameters that will be robust to the presence of regressor endogeneity. We discuss this further below.

We characterize deviations from the shared trend in consumption, labor income and 
assets as transitory movements in wealth. To understand this characterization, it is useful to relate our approach to the work of Cochrane (1994) who uses separate bivariate, cointegrated autoregressions to characterize the transitory components in GNP and stock prices. Using a consumption/GNP bivariate autoregression he shows that the consumption/GNP ratio is a potent forecaster of GNP growth, while consumption is nearly a random walk. Analogously, using a dividend/stock price bivariate autoregression he shows that dividend/price ratios forecast returns while dividends are nearly a random walk. The former result is interpreted using a simple permanent income model, the latter using a present value-dividend smoothing model.

The model of this paper is an alternative that brings these concepts together in a single trivariate system. The framework we investigate generalizes the simple permanent income model because it allows for time-varying expected returns. As we discuss in more detail below, we characterize deviations from the shared trend in consumption, labor income and assets as transitory movements in wealth, rather than as transitory movements in consumption or labor income, because they forecast asset growth, while consumption and labor income follow relatively persistent processes. We show that this forecastability of the growth in asset wealth is driven by the forecastability of expected stock returns, consistent with the theoretical framework we present.

In the empirical macroeconomic literature, consumption behavior has traditionally been studied using models that assume expected asset returns are constant over time, as in the permanent income framework of Hall (1978) and Flavin (1981). These models rule out any linkage between forecastable movements in asset returns and real consumption. The model we investigate retains much of the permanent income flavor, but allows us to directly connect the optimizing behavior of consumers with future stock returns. When consumption is below its shared trend with assets and labor income, the framework implies that consumers must be expecting returns to fall. When consumption is above its long term trend with assets and labor income, the framework implies that consumers must be expecting returns to rise. By factoring these expectations into current consumption, agents can insulate future consumption from transitory fluctuations in market returns.

The rest of the paper is organized as follows. The next section presents the consumption- 
based framework linking consumption, aggregate wealth and expected returns, and shows how we express the important predictive components of the consumption-aggregate wealth ratio in terms of observable variables. In section 3 , we present the results of estimating the trend relationship among consumption, labor income, and nonhuman wealth, and discuss how our method of detrending assets is related to the approach of Cochrane (1994). We then move on to test the important implication of the model presented in Section 2, that deviations from trend asset wealth are likely to lead stock returns. Section 4 discusses the data used in our forecasting regressions for asset returns and presents some summary statistics. Sections 5 and 6 document our main findings on the predictability of stock returns, while section 7 presents some results on the out-of-sample forecasting performance of the detrended wealth measure. Section 8 concludes.

\section{A Consumption Framework}

This section presents a general framework linking consumption, nonhuman wealth and labor income with expected returns. We build off the forward-looking model of consumer behavior developed previously in Campbell and Mankiw (1989) and Campbell (1993).

Consider a representative agent economy in which all wealth, including human wealth, is tradable. Let $W_{t}$ be aggregate wealth (human and nonhuman) in period $t . C_{t}$ is consumption and $R_{w, t+1}$ is the net return on aggregate wealth. The accumulation equation for aggregate wealth may be written ${ }^{3}$

$$
W_{t+1}=\left(1+R_{w, t+1}\right)\left(W_{t}-C_{t}\right)
$$

We define $r \equiv \log (1+R)$, and use lowercase letters to denote log variables throughout. Campbell and Mankiw (1989) and Campbell (1993) show that, if the consumption-aggregate wealth ratio is stationary, the budget constraint may be approximated by taking a first-order Taylor expansion of the equation. The resulting approximation gives an expression for the

\footnotetext{
${ }^{3}$ Labor income does not appear explicitly in this equation because of the assumption that the market value of tradable human wealth is included in aggregate wealth.
} 
$\log$ difference in aggregate wealth

$$
\Delta w_{t+1} \approx k+r_{w, t+1}+\left(1-1 / \rho_{w}\right)\left(c_{t}-w_{t}\right)
$$

where $\rho_{w}$ is the steady-state ratio of invested to total wealth, $(W-C) / W$, and $k$ is a linearization constant that plays no role in our analysis. ${ }^{4}$ Solving this difference equation forward and imposing that $\lim _{i \rightarrow \infty} \rho_{w}^{i}\left(c_{t+i}-w_{t+i}\right)=0$, the log consumption-wealth ratio may be written

$$
c_{t}-w_{t}=\sum_{i=1}^{\infty} \rho_{w}^{i}\left(r_{w, t+i}-\Delta c_{t+i}\right) .
$$

Equation (3) holds simply as a consequence of the agent's intertemporal budget constraint and therefore holds ex-post, but it also holds ex-ante. Accordingly, we can take conditional expectations of both sides of (3) to obtain

$$
c_{t}-w_{t}=E_{t} \sum_{i=1}^{\infty} \rho_{w}^{i}\left(r_{w, t+i}-\Delta c_{t+i}\right) .
$$

Equation (4) shows that the consumption-wealth ratio is a function of expected future returns to the market portfolio in a broad range of optimal consumption models, where the information set upon which expectations are conditioned will depend on the state variables in the model. These models may differ according to their specification of preferences, or according to what assumptions are made about the stochastic properties of consumption and asset returns, but all of them imply that the consumption-aggregate wealth ratio is a function of expected future returns. We now discuss a few of these models.

One widely used model of consumption behavior may be obtained by combining (3) with the presumption that consumers maximize the discounted sum of expected future power utility functions. ${ }^{5}$ In this case, the log first-order condition for optimal consumption choice is given by

$$
E_{t} \Delta c_{t+1}=\mu_{t}+\sigma E_{t} r_{w, t+1}
$$

\footnotetext{
${ }^{4}$ We omit unimportant linearization constants in the equations from now on.

${ }^{5}$ More generally, (5) may be obtained by assuming that agents maximize the discounted sum of objective functions specified by Epstein and Zin (1989), which retains many of the attractive features of power utility, but breaks the link between the parameters governing risk aversion and intertemporal substitution.
} 
where $\sigma$ is the elasticity of intertemporal substitution (EIS) and $\mu_{t} \equiv \operatorname{Var}_{t}\left[\Delta c_{t+1}-\sigma r_{w, t+1}\right] .^{6}$ Combining (4) and (5) shows that this model has a simple log-linear solution where the log consumption-wealth ratio takes the form

$$
c_{t}-w_{t}=(1-\sigma) E_{t} \sum_{i=1}^{\infty} \rho_{w}^{i}\left(r_{w, t+i}-\mu_{t+i}\right) .
$$

Equation (6) shows that the log consumption-aggregate wealth ratio summarizes the expectations of future returns to wealth. The log consumption-aggregate wealth ratio depends on the discounted sum of expected returns to total wealth multiplied by $1-\sigma$. With $\sigma>1$, an increase in returns lowers the log consumption-wealth ratio because substitution effects outweigh income effects; with $\sigma<1$, income effects dominate and high returns increase consumption relative to wealth. If $\sigma=1$ the two effect exactly offset and the consumptionwealth ratio is constant.

Other specifications of consumer preferences also give rise to a relationship between $c_{t}-w_{t}$ and expected future returns on the market portfolio. For example, a more complicated, but similar expression for the consumption-aggregate wealth ratio may be obtained using the preferences assumed in Campbell and Cochrane (1999) which generates time-varying risk aversion. Campbell and Cochrane add an external consumption "habit" to the standard power utility function; the utility function takes the form $\frac{\left(C_{t}-X_{t}\right)^{1-\gamma}-1}{1-\gamma}$, where $X_{t}$ is the external habit and the surplus consumption ratio is defined as $S_{t} \equiv \frac{C_{t}-X_{t}}{C_{t}}$. Using these preferences and the evolution equation for the log surplus consumption ratio assumed by Campbell and Cochrane, the log consumption-aggregate wealth ratio may be expressed

$$
\begin{array}{r}
c_{t}-w_{t}=E_{t} \sum_{i=1}^{\infty} \rho^{i}\left[r_{w, t+i}-\mu_{t+i}+\sigma_{t-1+i} E_{t-1+i} r_{w, t+i}+\right. \\
\gamma(1-\phi)\left(\bar{s}-s_{t-1+i}\right)- \\
\left.\gamma \lambda\left(s_{t-1+i}\right)\left(c_{t+i}-E_{t-1+i} c_{t+i}\right)\right],
\end{array}
$$

where $\mu_{t+i}$ contains the time-varying second moments of $\Delta c_{t}, \Delta s_{t}$, and $r_{w, t} ; \sigma_{t-1+i}$ is a timevarying parameter which is a function of $s_{t} ; \bar{s}$ is the mean log surplus consumption ratio,

\footnotetext{
${ }^{6}$ This solution may be obtained exactly if returns and consumption are assumed to be jointly lognormally distributed, and it holds approximately without distributional assumptions by taking a second-order Taylor expansion.
} 
and $\phi$ is a parameter governing the evolution of $s_{t} \cdot{ }^{7}$ According to their parameterization, the conditional expectation of consumption growth is constant, and (7) collapses to (within a constant of) (4).

Although the formulations in (6) and (7) can not be considered consumption solution (the parameters $\sigma_{t+1-i}, \mu_{t+i}$, and $s_{t}$ depend on consumption), they share the common implication that the log-consumption aggregate wealth ratio is a function of expected future returns on the market portfolio. Moreover, models in which returns have time-varying second moments, as in (6), and time-varying risk aversion, as in (7), also imply that the consumption-aggregate wealth ratio may be a function of expected future excess returns over the risk-free rate, or risk premia.

Because aggregate wealth is not observable, however, none of the models above are directly suited in their current form for predicting asset returns. Although the nonhuman wealth component in aggregate wealth may be approximated by an index of common stocks, there is no such readily observable measure of human capital.

Rather than proposing an explicit proxy for human capital, we pursue a strategy which allows us to express the important predictive components of $c_{t}-w_{t}$ for future market returns in terms of observable variables. Our approach begins with the assumption that aggregate labor income, $Y_{t}$, may be well described by the product of a stationary simple net return to human capital, $R_{h, t}$, times the stock of human wealth, $H_{t}{ }^{8}$ Thus, the nonstationary component of human capital is captured by labor income itself. Put another way, labor income is the annuity value of human wealth, $Y_{t}=R_{h, t} H_{t}$, or in $\operatorname{logs}, y_{t}=\log R_{h, t}+h_{t}{ }^{9}$ Note that (ignoring a linearization constant) $r_{h, t} \equiv \log \left(1+R_{h, t}\right) \approx 1 / \rho_{y}\left(y_{t}-h_{t}\right)$, where

\footnotetext{
${ }^{7} \sigma_{t-1+i}=\frac{1}{\gamma\left(1+\lambda\left(s_{t+1-i}\right)\right)}$, where $\lambda\left(s_{t-1+i}\right)$ is the sensitivity function specified in Campbell and Cochrane.

${ }^{8}$ This definition uses the notational convention that the stock of human capital, $H_{t}$, is measured beginningof-period, while the return, $R_{h, t}$, denotes the return on the stock of human capital held from (the end of) time $t-1$ to time $t$.

${ }^{9} \mathrm{We}$ assume that real labor income may be described as total income from human capital, including both "capital gains" and "dividends". We think of dividends as the cash-flow from the stock of human capital while the price of human capital, for a given current cash flow, may fluctuate on the basis of changes in the expected future cash flows. Less generally, labor income can be thought of as simply the dividend to human capital if the price is not too volatile.
} 
$\rho_{y} \equiv \frac{1+Y / H}{Y / H}$. This specification is quite general. It places no restrictions on the functional form of expected or realized returns, and it makes no assumptions about the relationship between returns to human capital and returns to nonhuman capital, or assets. ${ }^{10}$

We are now in a position to express the consumption-aggregate wealth ratio in terms of observable variables. Let $A_{t}$ be nonhuman, or asset, wealth, and let $1+R_{a, t}$ be its gross return. Aggregate wealth is therefore $W_{t}=A_{t}+H_{t}$ and log aggregate wealth may be approximated as

$$
w_{t} \approx \omega a_{t}+(1-\omega) h_{t}
$$

where $\omega$ equals the average share of nonhuman wealth in total wealth, $A / W$. This ratio may also be expressed in terms of steady state labor income and returns as $R_{h} A /\left(Y+R_{h} A\right)$.

The return to aggregate wealth can be decomposed into the returns of its two components

$$
1+R_{w, t}=\omega_{t}\left(1+R_{a, t}\right)+\left(1-\omega_{t}\right)\left(1+R_{h, t}\right) .
$$

Campbell (1996) shows that (9) may be transformed into an approximate equation for log returns taking the form

$$
r_{w, t} \approx \omega r_{a, t}+(1-\omega) r_{h, t}
$$

We may plug (10) into any of the consumption wealth formulations discussed above, including the ex-ante budget constraint (4). To understand how preferences might influence the relationship between expected returns and the consumption-aggregate wealth ratio, it is useful to consider a specific set of preferences. For example, we may combine (10) with the expression for power preferences in (6) to obtain (again ignoring constants)

$$
c_{t}-\omega a_{t}-(1-\omega) h_{t}=(1-\sigma) E_{t} \sum_{i=1}^{\infty} \rho_{w}^{i}\left(\omega r_{a, t+i}+(1-\omega) r_{h, t+i}-\mu_{t+i}\right) .
$$

This equation still contains the unobservable variable human wealth on the left hand side. To remove it, we substitute our formulation for the log of labor income into (11) which yields

\footnotetext{
${ }^{10}$ This assumption ignores effects that arise from an endogenous choice of labor supply in models where utility over leisure and consumption is non-separable.
} 
an approximate equation describing the log consumption-aggregate wealth ratio using only observable variables

$$
\begin{aligned}
c_{t}-\omega a_{t}-(1-\omega) y_{t}= & \\
& (1-\sigma) E_{t} \sum_{i=1}^{\infty} \rho_{w}^{i}\left(\omega r_{a, t+i}+(1-\omega) r_{h, t+i}-\mu_{t+i}\right)-(1-\omega) \rho_{y} r_{h, t} .
\end{aligned}
$$

The expression for the model with time-varying risk aversion, (7), is analogous. We denote the trend deviation, $c_{t}-\omega a_{t}-(1-\omega) y_{t}$ as cayt.

These deviations from the common trend in consumption, asset wealth and labor income are produced by movements in the consumption-aggregate wealth ratio. Because we find that these trend deviations are largely driven by fluctuations in nonhuman wealth, rather than by movements in consumption or labor income, we may use consumption and labor income to detrend assets and think of deviations from this common trend as transitory movements in asset wealth. We discuss this further in the next section.

The sign of the correlation between cayt and expected future returns depends on the value of the elasticity of intertemporal substitution. This may be seen most clearly in (12) where the EIS is a constant. In cases where the EIS is not constant, such as in $(7), \sigma_{t}$ may be parameterized so that its mean value is close to zero, as in Campbell and Cochrane (1999). Several researchers have estimated the EIS and typically find that is quite small, indeed close to zero (for example, Campbell and Mankiw 1989; Hall 1988 ). As long as $\sigma$ is less than one, the income effect dominates and the equations above imply that cayt should be positively correlated with expected future returns, consistent with what we find below. When $a_{t}$ and $y_{t}$ decline below their customary ratio with $c_{t}$ (cayt is rises), investors must be expecting some combination of high future returns on human and nonhuman wealth. ${ }^{11}$

Equation (12) implies that the difference between log consumption and a weighted average of log asset wealth and log labor income summarizes investors' expectations of future returns

\footnotetext{
${ }^{11}$ This statement abstracts from the terms that do not involve returns in equations (6)-(7). These terms will typically be small relative to the discounted value of returns to aggregate wealth, however, and it should be noted that the terms involving $s_{t}$ and $\sigma_{t}$ in $(7)$ will have mean values that are close to zero according to the model in Campbell and Cochrane (1999).
} 
to human and nonhuman capital. When $\sigma<1$, this deviation from the shared trend in consumption, labor income and wealth plays a role for expected returns that is similar to that played by deviations from the shared trend in consumption and total (labor and asset) income for expected labor income growth in a simple permanent income model where returns are assumed constant (Campbell 1987). In the simple permanent income model, savings, equal to total income minus consumption, is a function of expected future declines in labor income. If labor income is expected to fall in the future, consumption will dip temporarily below total income (saving will rise) as households attempt to insulate future consumption from the expected decline. The consumption framework explored above generalizes the permanent income model because it allows for variation in returns, but has analogous implications. ${ }^{12}$ In the present framework, if returns to human and nonhuman capital are expected to decline in the future, consumption will dip temporarily below its long term relationship with both assets and labor income as households attempt to insulate future consumption from lower returns. In the simple permanent income model, households save for a "rainy day" in labor income growth; in the model above, they save for a rainy day in returns to human and nonhuman capital.

Equation (12) also shows that cayt will be a good proxy for market expectations of future asset returns, $r_{a, t+i}$, as long as expected future returns on human capital, $r_{h, t+i}$, and the second moments in $\mu_{t+i}$ are not too variable, or as long as these variables are highly correlated with expected returns on assets.

It is instructive to compare (12) to an expression for another variable that has been widely used to forecast asset returns, the log dividend-price ratio. Let $d_{t}$ and $p_{t}$ be $\log$ dividend and log price, respectively, of the stock of asset wealth. Campbell and Shiller (1988) show that the log dividend-price ratio may be written

$$
d_{t}-p_{t}=E_{t} \sum_{j=1}^{\infty} \rho_{a}^{j}\left(r_{a, t+j}-\Delta d_{t+j}\right)
$$

where $\rho_{a}=P /(P+D)$. This equation is often referred to as the 'dynamic dividend growth

\footnotetext{
${ }^{12}$ This generalization we make here is simply that expected returns are allowed to vary over time, it does imply that the current model nests the permanent income model considered in Campbell (1987) which has quadratic preferences.
} 
model' and is derived by taking a first-order Taylor approximation of the equation defining the $\log$ stock return, $r_{t}=\log \left(P_{t}+D_{t}\right)-\log \left(P_{t}\right)$. This equation says that if the dividendprice ratio is high, agents must be expecting either high returns on assets in the future or low dividend growth rates.

Note the likeness of this equation to (4). Like (4), equation (13) holds ex-post as well as ex-ante. The role of consumption in (4) is directly analogous to that of $d_{t}$ in (13): when the consumption-aggregate wealth ratio is high, agents must be expecting either high returns on the market portfolio in the future or low consumption growth rates. Thus, consumption may be thought as the dividend payed from human and nonhuman wealth. Unlike dividends in the Campbell Shiller model, however, the determinants of consumption are more readily defined by theory and we can combine the budget constraint formulation in (4) with various models of consumer behavior to obtain expressions like (7) or (12).

The dividend-price ratio of asset wealth (usually approximated by a broad stock market index) summarizes the expectations of future dividend growth and returns to asset wealth. Just as with the trend deviation on the left-hand-side of (12), equation (13) shows that the log dividend-price ratio should forecast asset returns. If expectations of future dividend growth rates are not too variable, the dividend-price ratio should be a good predictor of asset returns. Analogously, if future returns to human capital and the second moments contained in $\mu_{t+i}$ are not too variable, the trend deviation term in (12) should be a good predictor of asset returns. Each variable is a noisy predictor of asset returns but contains different sources of noise. In this way, the log dividend-price ratio and the log consumption-aggregate wealth ratio may contain independent information for forecasting returns at different horizons. We investigate this possibility below. 


\section{Estimating the Trend Relationship Among Consump- tion, Labor Income and Nonhuman Wealth}

An important task in using the left-hand-side of (12) to forecast asset returns is the estimation of the parameters of the shared trend in consumption, labor income and wealth in (12). ${ }^{13}$ At first glance, it may appear that obtaining a consistent estimate of these parameters would be difficult since the regressors $a_{t}$ and $y_{t}$ are likely to be endogenously determined. This section discusses how we apply the asymptotic properties of cointegrated variables to circumvent this difficulty.

Before estimating the parameters of the shared trend, we deal with a measurement issue that arises from the nature of the data on consumption. Previous empirical work which has investigated consumption-based models like that which we explore has used expenditures on nondurables and services as a measure of consumption. The use of these expenditure categories is justified on the grounds that the theory applies to the flow of consumption; expenditures on durable goods are not part of this flow since they represent replacements and additions to a stock, rather than a service flow from the existing stock. But since nondurables and services expenditure is only a component of consumption, the standard solution to this problem requires the researcher to assume that total consumption is unobservable and a constant multiple of nondurable and services consumption (Campbell 1987; Blinder and Deaton 1985; Galí 1990).

We follow in this tradition and use nondurables and services as our consumption measure, and assume a constant scale factor governing the relationship between the log of total consumption and the $\log$ of nondurables consumption, denoted $c_{n, t}$. Thus we write $\log$ total consumption, $c_{t}=\lambda c_{n, t}$, where $\lambda>1$, implying that the estimated cointegrating vector for $c_{n, t}, a_{t}$, and $y_{t}$ will be given by $\left[1,-\frac{1}{\lambda} \omega,-\frac{1}{\lambda}(1-\omega)\right] .{ }^{14}$ We define $\beta_{a}=\frac{1}{\lambda} \omega$, and $\beta_{y}=\frac{1}{\lambda}(1-\omega)$,

\footnotetext{
${ }^{13}$ This section draws heavily from Ludvigson and Steindel (forthcoming).

${ }^{14}$ Previous research has worked with formulations in levels, rather than in logs as we do here. Because Blinder and Deaton (1985) report that the share of nondurables and services in measured expenditures has displayed a secular decline over the sample period, the assumption that total consumption is a constant multiple of nondurable consumption may be questionable. By contrast, we postulate that the $\log$ of total
} 
the parameters of the cointegrating relation to be estimated. Note that $\beta_{a}+\beta_{y}$ identifies $1 / \lambda$.

The data used for this estimation are quarterly, seasonally adjusted, per capita variables, measured in 1992 dollars. ${ }^{15}$ As a preliminary step, we test whether each variable passes a unit root test. Given that consumption, labor income and household net worth all appear to contain a unit root, we then move on to test for the presence of cointegration in our sample 1952:4-1998:3. We provide the results of these tests in Appendix A, and simply note here that there is strong evidence supporting the hypothesis of a single cointegrating vector for consumption, labor income and wealth.

To estimate $\beta_{a}$ and $\beta_{y}$, we employ a method that generates optimal estimates of the cointegrating parameters in a multivariate setting. One approach to estimating these parameters would be to simply run an ordinary least squares $(O L S)$ regression of $c_{n, t}$ on $y_{t}$ and $a_{t}$. It is now well recognized, however, that standard $O L S$ estimates are not asymptotically optimal. We follow Stock and Watson (1993) and use a dynamic least squares ( $D L S)$ technique which specifies a single equation taking the form

$$
c_{n, t}=\alpha+\beta_{a} a_{t}+\beta_{y} y_{t}+\sum_{i=-k}^{k} b_{a, i} \Delta a_{t-i}+\sum_{i=-k}^{k} b_{y, i} \Delta y_{t-i}+\epsilon_{t},
$$

where the symbol $\Delta$ is the first difference operator.

Equation (14) is estimated by $O L S$, and this methodology provides a consistent estimate of the cointegrating parameters through its estimates of $\beta_{a}$ and $\beta_{y}$. Note that a standard $O L S$ regression of consumption on labor income and nonhuman wealth also provides a consistent consumption is a constant multiple of the log of nondurable and services consumption. Unlike the ratio of levels, the ratio of logs appears to have exhibited little secular movement during our sample period.

${ }^{15}$ The consumption data are for nondurables and services excluding shoes and clothing in 1992 chain weighted dollars. The nonhuman wealth data is the household net worth series provided by the Board of Governors of the Federal Reserve. Labor income is defined as wages and salaries plus transfer payments plus other labor income minus personal contributions for social insurance minus taxes. Taxes is defined as (wages and salaries/ (wages and salaries + proprietors income with IVA and Ccadj + rental income + personal dividends + personal interest income))*personal tax and non tax payments. Both the net worth variable and the labor income variable are deflated by the PCE chain-type price deflator. 
estimate of the cointegrating parameters. The $D L S$ specification adds leads and lags of the first difference of the right hand side variables to eliminate the effects of regressor endogeneity on the distribution of the least squares estimator. We also make a Newey-West correction to the $t$-statistics for generalized serial correlation of the residuals.

It is important to recognize that estimates of $\beta_{a}$ and $\beta_{y}$ will be consistent despite the fact that $\epsilon_{t}$ will typically be correlated with the regressors $a_{t}$ and $y_{t}$. In ordinary empirical applications this is not the case, and regressor endogeneity is often an intractable problem that may lead to incorrect inferences about the parameters one seeks to estimate. Applications involving cointegrated variables, however, have an important and unusual property: ordinary least squares estimates of cointegrating parameters are robust to the presence of regressor endogeneity. This follows from the fact that $O L S$ estimates of cointegrating parameters are "superconsistent", converging to the true parameter values a rate proportional to the sample size $T$ rather than proportional to $\sqrt{T}$ as in ordinary applications (Stock 1987). ${ }^{16}$ This means that the data should provide a consistent estimate of $\omega$, in effect making observable the average ratios of each component of wealth.

Implementing the regression in (14) using data from the fourth quarter of 1952 to the third quarter of 1998 generates the following point estimates (ignoring coefficient estimates on the first differences) for the parameters of the shared trend consumption, labor income and wealth,

$$
c_{n, t}=0.68+0.28 a_{t}+0.62 y_{t}
$$

where the corrected $t$-statistics appear in parentheses below the coefficient estimates. ${ }^{17}$ The

\footnotetext{
${ }^{16}$ These results apply asymptotically. As Campbell and Perron (1991) emphasize, however, finding evidence of cointegration in a given sample suggests that the data set contains a sufficiently large number of observations that the researcher may, in practice, exploit the asymptotic results in finite samples of the size encountered.

${ }^{17}$ We experimented with various lead/lag lengths in estimating the $D L S$ specification. For the results reported in (15), the value of $k=2$ was used. Neither the cointegrating parameter estimates nor the forecasting results we present below are sensitive to the particular value of $k$ for $k$ ranging from 1 to 8 . Similar estimates of the cointegrating parameters were also obtained using Johansen's (1988) full information
} 
coefficient estimates suggest that $\lambda$ is about 1.10, implying that the share of nonhuman capital in aggregate wealth is close to one-third, while the share of human capital is close to two-thirds. We denote the estimated trend deviation by $\widehat{c a y}_{t} \equiv c_{n, t}-\widehat{\beta}_{a} a_{t}-\widehat{\beta}_{y} y_{t}$ where hats denote estimated parameters.

How can we interpret deviations from the shared trend in consumption, labor income and assets? We mentioned above that we characterize the estimated trend deviation, $\widehat{c a y}_{t}$, as transitory variation in asset wealth. To clarify this interpretation, it is useful compare our approach to that of Cochrane (1994) who uses separate bivariate autoregressions - one for consumption and GNP, and one for stock prices and dividends - to characterize the transitory components in GNP and stock prices. Each of these pairs of variables are cointegrated, and the errors in the bivariate cointegrating relationships, that is the log consumption-GNP ratio and the log dividend-price ratio, predict GNP growth and stock returns, confirming that each of these variables has important transitory components.

To interpret transitory movements in GNP, Cochrane uses a simple permanent income model which implies that consumption and total income should be cointegrated; to interpret the transitory movements in stock prices he use a present value-dividend smoothing model which implies that dividends and prices should be cointegrated. Because the permanent income model assumes that returns are constant, however, it cannot account for the forecastability of stock returns that the present value-dividend smoothing model can. By contrast, the dividend-smoothing model cannot account for the forecastability of GNP growth by the log consumption-GNP ratio because it does not explicitly model the link between consumption and dividends. For this reason, Cochrane uses separate bivariate, cointegrated vector autoregressions (VARs) to study the dynamic properties of output and stock prices.

Rather than using two bivariate systems to study these features of the data, the model of this paper is an alternative that brings these concepts together in a single trivariate system. The framework provides both a model of the optimal consumption decision and allows for time-varying returns, implying that consumption, asset wealth and labor income maximum-likelihood technique. 
are cointegrated and that the error in this shared trend predicts returns to asset wealth and human capital, provided that there are indeed predictable, or transitory, components in these returns.

To investigate the properties of this trivariate system, it is instructive to examine a three-variable, cointegrated vector autoregression where the log difference in consumption, asset wealth and labor income are regressed on their lags and an error-correction term, the estimated lagged trend deviation, $\widehat{c a y}_{t-1}$. We focus on the relationship between the estimated trend deviation and future growth rates of each variable. Table 1 presents these results using a two lag VAR. ${ }^{18,19}$ Note that, in this cointegrated autoregression, as well as in the forecasting regressions for asset returns presented in the next section, standard errors do not need to be adjusted to account for the use of the generated regressor, $\widehat{c a y}_{t-1}$. Again, this follows from the fact that estimates of the cointegrating parameters converge to their true values at rate $T$, rather than at the usual rate $\sqrt{T}$ (see Stock 1987; Campbell and Perron, 1991). The table reveals at least two interesting properties of the data on consumption, household wealth and labor income.

First, estimation of the asset growth equation shows that $\widehat{c a y}_{t-1}$ predicts asset growth, implying that deviations in assets from its shared trend with labor income and consumption uncover important transitory variation in wealth. In section 5 below we show that this variable predicts asset growth because the estimated trend deviation forecasts asset returns, consistent with the theoretical framework discussed above.

A second feature of the data is revealed by inspecting the consumption and labor income growth regressions. As Cochrane (1994) emphasizes, transitory variation in the (log) levels of a series requires forecastability of the growth rates. Both consumption and labor income growth are somewhat predictable by lags of consumption growth, as noted elsewhere (Flavin 1981; Campbell and Mankiw 1989), but the adjusted $R^{2}$ statistics-especially for the labor income equation-are lower than that in the asset regression. More importantly, the magnitude of the coefficient on the trend deviation, $\widehat{c a y}_{t-1}$, in the asset growth equation is substantially larger than in either the consumption or labor income equation. Further-

\footnotetext{
${ }^{18}$ This lag length was chosen in accordance with findings from Akaike and Schwartz tests.

${ }^{19}$ This system is also studied in Ludvigson and Steindel (forthcoming).
} 
more, this error-correction term does not enter statistically significantly in the consumption growth equation, and is significant only at the $10 \%$ level in the labor income growth equation. ${ }^{20}$ Other specification tests (not reported) suggest that consumption and labor income are both very persistent and close to random walks.

Taken together, these considerations suggest that deviations from the shared trend in consumption, labor income and assets are better described as transitory movements in asset wealth than as transitory movements in consumption or labor income. When log consumption deviates from its habitual ratio with log labor income and log assets, it is asset wealth, rather than consumption or labor income, that is forecast to adjust until the equilibrating relationship is restored. In this way, we may interpret consumption and labor income as defining the trend in assets much in the same way that Cochrane interprets consumption as defining the trend in GNP, and dividends as defining the trend in stock prices.

The next step in our analysis is to investigate the role of transitory movements in asset wealth in forecasting asset returns. Before doing so, we discuss the data used in this investigation and examine summary statistics for $\widehat{c a y}_{t}$ and for our financial data.

\section{Asset Return Data}

Our financial data include stock returns, dividends per share and quarterly earnings per share from the Standard \& Poor's (S\&P) Composite index for which quarterly earnings data are available. In addition we also consider returns on the value-weighted CRSP index (CRSP-VW). The CRSP index (which includes the NYSE, AMEX and NASDAQ) should provide a better proxy for nonhuman component of total asset wealth since it is a much broader measure than is the $\mathrm{S} \& \mathrm{P}$ index.

Let $r_{t}$ denote the log real return of the index under consideration and $r_{f, t}$ the return on the 30-day Treasury bill (the 'risk-free' rate). The log excess returns is measured as $r_{t}-r_{f, t}$.

\footnotetext{
${ }^{20}$ Note that Cochrane (1994) found that the log consumption-GNP ratio forecasts GNP growth, of which labor income growth is one component. Since asset returns and labor income are both components of national income, the bivariate approach does not reveal which components may be more highly forecastable by the error-correction term.
} 
Log price, $p$ is the natural logarithm of the relevant index. Log dividends, $d$, are the natural logarithm of the sum of the past four quarters of dividends per share. Log earnings, $e$, are the natural logarithm of a single quarter's earnings per share. We call $d-p$ the dividend yield and, following Lamont (1998), $d-e$ the payout ratio.

Table 2 presents summary statistics for the variables mentioned above and for the relative bill rate, the T-bill rate minus its 12 month backward moving average. Campbell (1991) and Hodrick (1992) apply this stochastic detrending method to T-bills in order to forecast returns.

The properties of stock returns, $d-p, d-e$ and the relative bill rate are well-known, thus we focus our discussion on the estimated trend deviation variable $\widehat{c a y}$. This variable is contemporaneously positively correlated with excess stock returns, the dividend-price ratio and the dividend-earnings ratio. The correlation with the relative bill rate is negative. However, none of the correlations are large (in absolute value). Relative to its mean, $\widehat{c a y}$ varies less than $d-p$ and $d-e$.

How does the persistence of $\widehat{c a y}_{t}$ compare to other variables known to forecast excess stock returns? It is well-known that the price-dividend ratio is very persistent. The autocorrelation of $\widehat{c a y}_{t}$ is fairly high but substantially lower than for $d-p, 0.77$ compared to 0.92 . What factors might be at the root of this difference in autocorrelation?

To address this question, we consider a simple illustrative example comparing (12) and (13). ${ }^{21}$ For the moment we ignore the $\rho_{y} r_{H, t}$ term in (12) and suppose the expected log return on each component of wealth may be well described by a first-order autoregressive process. That is, $E_{t} r_{a, t+1}=x_{t}$ and $E_{t} r_{h, t+1}=g_{t}$, where $x_{t}=\phi x_{t-1}+\varepsilon_{t}$ and $g_{t}=\psi g_{t-1}+\eta_{t}$. Taken together, these assumptions imply that the expected return on the market portfolio is given as $E_{t} r_{w, t+1}=\omega x_{t}+(1-\omega) g_{t} \equiv z_{t}$. The data suggest that the first-order autocorrelation of $d_{t}-p_{t}, \phi$, is 0.92 while the first order autocorrelation of $z_{t}$ should be 0.77 . Assuming that $x_{t}$ and $g_{t}$ have equal variances and a correlation coefficient of 0.5 , then $\psi$, the first order autocorrelation of $E_{t} r_{h, t+1}$ should equal $0.71 .^{22}$

\footnotetext{
${ }^{21}$ For the purpose of this example we assume that $\mu_{t}$ is a constant and that log-dividends follow a random walk; assuming a stationary process for the first difference of log dividends would not change the main conclusions.

${ }^{22}$ This exercise produces similar results for different values of the relative variance of $x$ and $y$ and their
} 
Accordingly, the differences in autocorrelation between $d_{t}-p_{t}$ and $\widehat{c a y}_{t}$ may be reconciled if the expected log return to human capital is less persistent than the expected log return to nonhuman capital. ${ }^{23}$ Of course, this example is only suggestive, but it raises the possibility that differences in persistence between equations (12) and (13) may be driven by differences in the stochastic processes governing expected returns on human and nonhuman capital.

Figure 1 plots the standardized trend deviation, $\widehat{c a y}_{t}$, and the standardized excess return on the S\&P Composite Index over the period spanning the fourth quarter of 1952 to the third quarter of 1998. The figure shows a multitude of episodes during which positive trend deviations preceded large positive excess returns and negative ones preceded large negative returns. Moreover, large swings in the trend deviation tend to precede spikes in excess returns. This pattern is evident during the 1950s and early 1960s when $\widehat{c a y}_{t}$ shot up prior to a sequence of up-ticks in excess returns, during the 1970s when sharp declines in $\widehat{c a y}_{t}$ led the bear markets of those years, and during the 1980s when the trend deviation turned negative prior to the 1987 stock market crash. The trend deviation term also displays some notable cyclicality, typically rising during recessions and falling during booms.

To some extent, the tight link exhibited between these variables appears to have broken down in the most recent period; $\widehat{c a y}_{t}$ became negative in 1995 and declined sharply until the second quarter of 1998, while the stock market-in a delayed response relative to its historical pattern-did not turn down until the third quarter of 1998.

Perhaps the most striking feature of the Figure 1 is how foreboding are current levels of $\widehat{c a y}_{t}$ for returns in 2000 and beyond. This model is not alone in exhibiting such a bearish projection; the log dividend-price ratio is well below its historical mean, indeed at a post-war low in our S\&P data. Thus, the dynamic-dividend growth model of Campbell and Shiller (13) implies that dividend growth would have to be implausibly high to rationalize the view that returns should not be expected to fall going forward. Of course, we cannot preclude covariance.

${ }^{23}$ These results were obtained by ignoring the $\rho_{y} r_{H, t}$ term in (12). Campbell, Lo and MacKinlay (1997) show that positive autocorrelation of expected returns may lead to negative autocorrelation of realized returns. Such negative serial correlation in $\rho_{y} r_{H, t}$ could also bring down the autocorrelation of $\widehat{c a y}_{t}$ relative to $d_{t}-p_{t}$. The influence of this one term on the persistence of $\widehat{c a y}_{t}$ seems likely to be small, however, relative to the influence of the discounted sum of many positively serially correlated expected returns. 
the possibility that a structural shift has occurred in the underlying parameters governing these relationships. Nevertheless, the unusually low values of $\widehat{c a y}_{t}$ in recent data suggests that consumers are expecting a stock market correction, and have already factored that expectation into today's consumption.

\section{$5 \quad$ Quarterly Forecasting Regressions}

We now move on to asses the forecasting power of detrended wealth for asset returns. In advance of presenting these findings, we note that the largest autoregressive root of $\widehat{c a y}_{t}$ is substantially less than one, close 0.8 . Thus the use of $\widehat{c a y}_{t}$ in the forecasting equations below does not present the inference problems that arise with other popular forecasting variables (e.g., the log dividend-price ratio) which are very persistent and contain roots much closer to unity. This is consistent with evidence displayed in Appendix A that consumption, assets and labor income are cointegrated.

Table 3 shows a typical set of results using the lagged trend deviation, $\widehat{c a y}_{t}$, as a predictive variable. The top panel of the table reports one-quarter ahead forecasts of the real return on the S\&P Composite Index and on the CRSP-VW Index. The bottom panel of the table reports these forecasts for excess returns. In each case, we ask whether $\widehat{c a y}_{t}$ "Granger causes" next period's return or excess return; we call these our benchmark regressions.

Focusing on the $\mathrm{S} \& \mathrm{P}$ composite index, the first row of each panel of Table 3 shows that the forecasting power of a regression of returns on one lag of the dependent variable is quite weak. This model predicts only 1 percent of next quarter's variation in real returns, and a negligible percent of next quarter's excess return variation. By contrast, the trend deviation explains a substantial fraction of the variation in next quarter's return. For the S\&P Composite Index, regressions of real returns and excess returns on their own lags and on one lag of $\widehat{c a y}_{t}$ both produce an adjusted $R^{2}$ of $9 \%$, so that adding last quarter's value of $\widehat{c a y}_{t}$ to the model allows the regression to predict an additional 9 percent of the variation in next period's excess return and an extra $8 \%$ of the variation in next period's real return. Moreover, the Newey-West corrected $t$-statistic for this variable indicates that the coefficient estimate is nonzero with very high probability. These results are little affected by whether 
the lagged value of the real return is included in the regression as an additional explanatory variable (row 3 ).

The predictive impact of $\widehat{c a y}_{t}$ on future returns is economically large: the point estimate of the coefficient on $\widehat{c a y}_{t}$ is about 2.2 for real returns. To understand these units, note that the variables comprised in $\widehat{c a y}_{t}$ are in per-capita terms, measured in billions of 1992 dollars and that $\widehat{c a y}_{t}$ itself has a standard deviation of about 0.01 . Thus a one-standard deviation increase in $\widehat{c a y}_{t}$ leads to a 220 basis point rise in the expected real return on the S\&P index and about the same rise in the excess return, roughly a 9 percent increase at an annual rate.

The regressions considered so far use the one-period lagged value of the trend deviation as regressor. Relative to financial variables, macroeconomic variables are reported with a lag of about one month. The sixth column in each panel shows regression results when the one-quarter lagged value, $\widehat{c a y}_{t}$, is replaced with the two-quarter lagged value, $\widehat{c a y}_{t-1}$, as an predictive variable. Due to the serial correlation in $\widehat{c a y}_{t}$, the coefficient on the two-period lagged variable is also strongly statistically significant, but the point estimate falls to about 1.6. And, although, as would be expected, the $\bar{R}^{2}$ is somewhat lower than when the oneperiod lagged value is used, including the two-period lagged value of $\widehat{c a y}_{t}$ into the benchmark equation still allows the regression to pick up an additional 5 percent of the variation in both next quarter's raw and excess return.

Using the broader CRSP value-weighted (CRSP-VW) index as a measure of returns produces slightly higher $\bar{R}^{2}$ statistics than for the S\&P 500 index. The $t$-statistics of the $\widehat{c a y}_{t}$ coefficients increase to over 4 , for both real returns and excess returns. According to the consumption framework presented above, $\widehat{c a y}_{t}$ forecasts expectations of future returns to the market portfolio, so it is not surprising that it forecasts the broader CRSP-VW index better than the S\&P 500 index.

The results in Table 3 shows that transitory movements in asset wealth are positively correlated with the conditional first moment of excess returns. When log assets and log labor income are unusually low relative to log consumption ( $\widehat{c a y}_{t}$ rises), expected excess returns rise. This variation in $\widehat{c a y}_{t}$ is also countercyclical: its contemporaneous correlation with consumption growth and real GDP growth is -0.07 and -0.12 respectively, a phenomenon illustrated graphically in Figure 1 which shows that $\widehat{c a y}_{t}$ tends to decline during expansions 
and rise just prior to the onset of a recession. Accordingly, expansions are characterized by increasing consumption, but an even greater rate of increase in assets.

Interestingly, these features of the data may be plausibly interpreted using the timevarying risk aversion framework of Campbell and Cochrane (1999). In that model, consumption booms are periods during which consumption increases above habit, leading to a decline in risk aversion. The decline in risk aversion leads, in turn, to a greater demand for risky assets and a decrease in expected excess returns, or risk premia. Thus, in that model, booms are times of rising consumption but declining ratios of consumption to wealth, consistent with what we find.

How robust are the results? Table 4 reports estimates from forecasting regressions which include a variety of variables shown elsewhere to contain predictive power for excess returns. Shiller (1984), Fama and French (1988) and Campbell and Shiller (1988) all find that the ratios of price to dividends or earnings have predictive power for excess returns. Lamont (1998) finds that the ratio of dividends to earnings has forecasting power at quarterly horizons. Campbell (1991) and Hodrick (1992) find that the relative T-bill rate (the 30-day T-bill rate minus its 12-month moving average) predicts returns, and Fama and French (1989) study the forecasting power of the term spread (the 10-year Treasury bond yield minus the 1-year Treasury bond yield) and the default spread (the difference between the BAA and AAA corporate bond rates). We include these variables in the benchmark equations for the excess return on the S\&P Composite Index in Table $4 .{ }^{24}$

The first row of Table 4 shows that the dividend yield has an virtually no effect on excess returns at a horizon of one quarter; the $\bar{R}^{2}$ statistic for this regression is negligible. This is not surprising since it is by now well known that this variable typically performs better at forecast horizons in excess of two years (Campbell 1991, Campbell, Lo and MacKinlay, 1997). When we include the trend deviation in this regression with the dividend yield (row

\footnotetext{
${ }^{24}$ In other tests (not reported) we included the one-period lagged value of consumption growth, labor income growth and PCE inflation as predictive variables. None of these variables influence the coefficient estimates on $\widehat{c a y}_{t}$, or the incremental $\bar{R}^{2}$ from including $\widehat{c a y}_{t}$ in the regression. The former two are not statistically significant, and inflation, while individually significant, does not increase the explanatory power of the regression by a measurable amount.
} 
3), the $\bar{R}^{2}$ statistic increases to $9 \%$, and the point estimate on $\widehat{c a y}_{t}$ is strongly significant.

In a recent paper, Lamont (1998) argues that the dividend payout ratio should be a potentially potent predictor of excess returns, a result of the fact that high dividends typically forecast high returns whereas high earnings typically forecast low returns. The third row of Table 4 shows the regression results when both the lagged dividend yield, $d_{t}-p_{t}$, and the lagged dividend payout ratio, $d_{t}-e_{t}$, are included in the forecasting equation. This regression has more explanatory power than the univariate model for returns used in Table 4 , but the $\bar{R}^{2}$ statistic is still just $2 \%$. Adding the trend deviation term, $\widehat{c a y}_{t}$, again significantly improves the one-quarter ahead predictive capacity of the regression; of the three, this variable is the only one with statistically significant explanatory power, and including it increases the $\bar{R}^{2}$ to $9 \%$.

The final row of the top panel in Table 4 augments the benchmark regression by including the lagged relative bill rate, the lagged term spread, and the lagged default spread along with the lagged dividend yield and the lagged payout ratio. Of these seven explanatory variables, the only ones that have significant marginal predictive power are the relative bill rate and the trend deviation term. Both the trend deviation and the relative bill rate are highly significant, and the estimated coefficient on the relative bill rate has the expected negative sign. Nevertheless, a comparison of rows 4 and 5 makes clear that the relative bill rate, while having marginal explanatory power, does not help explain much of the variation in next quarter's excess return. The $\bar{R}^{2}$ including this variable (row 5) is 10 percent, just 1 percent higher than in row 4 where the variable is excluded (the unadjusted $R$-squared statistics are similar). Furthermore, the coefficient estimate for $\widehat{c a y}_{t}$ is little affected by the inclusion of the relative bill rate or other variables in the forecasting equation; regardless of which specification we consider, the point estimates are always between 1.9 and 2.3 and the $t$-statistics are above 3 . This reveals that $\widehat{c a y}_{t}$ contains information about future asset returns that is not included in other well known forecasting variables.

Our results on the forecasting power of the dividend payout ratio and the dividend yield differ from those of Lamont (1998). He reports that both variables are strong predictors of the excess return on the $\mathrm{S} \& \mathrm{P}$ index and he reports an (unadjusted) $R^{2}$ of $13 \%$ in a regression 
using these indicators as explanatory variables.

We investigate these differences in the last two rows of Table 4, which change the sample period to more closely match that of Lamont's. Lamont's data spanned the period from the first quarter of 1947 to the fourth quarter of 1994, whereas our data runs from the fourth quarter of 1954 to the fourth quarter of 1998. As the last two rows show, if we run our equations over the period corresponding roughly to Lamont's sample (we do not have data for $a_{t}$ before 1952:4) we obtain results very similar to those obtained in that paper. In this case both the dividend yield and the payout ratio are strong predictors of next quarter's excess return, and the regression explains about $11 \%$ of next quarter's variation. The predictive power of $\widehat{c a y}_{t}$ over this shorter sample is somewhat higher than in the full sample, with the $\bar{R}^{2}$ from using this single variable as a predictor equal to 0.11 compared to 0.09 (Table 3) in the full sample. On the whole, however, the results for $\widehat{c a y}_{t}$ are very similar to those using the full sample: the trend deviation remains a strong marginal predictor of excess returns over this period and including it as an explanatory variable along with $d_{t}-p_{t}$ and $d_{t}-e_{t}$ increases the $\bar{R}^{2}$ statistic by $6 \%$ to $17 \%$. We now ask how detrended asset wealth compares to other forecasting variables as a predictor of returns over horizons greater than one quarter.

\section{Long Horizon Forecasts}

In this section, we investigate the relative predictive power of each variable just explored for returns at different horizons. In the next subsection we discuss the results of single-equation regressions of returns over various horizons on the important predictive variables considered above. This approach follows Fama and French (1988). Although this technique provides a direct estimate of the long-horizon properties of the data, it has been criticized for having poor statistical properties in finite samples. To address these finite sample difficulties, we explore, in the second subsection, the long-horizon characteristics of returns by using the Vectorautoregression (VAR) approach of Campbell (1991). 


\subsection{Single Equation Regressions}

Table 5 presents the results of regressions of returns over horizons spanning 1 to 24 quarters on lagged variables. The dependent variable in each regression is the $H$-period log excess return on the $\mathrm{S} \& \mathrm{P}$ Composite Index, $r_{t+1}-r_{f, t+1}+\ldots+r_{t+H}-r_{f, t+H}$. We start by using just the $\log$ dividend yield, $d_{t}-p_{t}$, as a regressor. We then move on to investigate the results for models which include, $d_{t}-p_{t}$ and $d_{t}-e_{t}$ together, $\widehat{c a y}_{t}$ by itself, and all three of these variables along with the relative bill rate. For each regression the table reports the estimated coefficient on the included explanatory variable(s), the adjusted $R^{2}$ statistic, and the Newey-West corrected $t$-statistic for the hypothesis that the coefficient is zero.

The top panel of Table 5 reports results from regressions of the log return on the S\&P Composite Index on to the lagged dividend yield. These results are consistent with those obtained elsewhere (for example, Fama and French 1988; Campbell, Lo and MacKinlay 1997). At a horizon of one quarter, the dividend yield displays little predictive power for returns, the $\bar{R}^{2}$ is negligible and the coefficient estimate is not significantly different from zero. The estimated coefficient on the log dividend-price ratio does not become significant until the return horizon is at least 4 quarters. Once the horizon is increased beyond 4 quarters, the predictive power of the dividend yield becomes much stronger. At a horizon of 8 quarters, the dividend yield predicts $8 \%$ of the variation in returns over that period, at a horizon of six years this number rises to $30 \%$. Thus, consistent with existing evidence, the dividend yield is a powerful forecaster of long-horizon returns but has little capacity to forecast short-horizon returns.

The next three panels of Table 5 gives an indication of the forecasting power of other variables for long-horizon returns. Panel 2 shows that the adding the dividend payout ratio to the equation produces results that are very similar to those using just the dividend yield. Each variable has an important impact on returns over horizons exceeding 8 quarters, but not on returns over shorter horizons. The $\bar{R}^{2}$ statistic suggests that these variables have their greatest predictive power at horizons of 3 years or more, explaining about $40 \%$ of the variation in returns at a six year horizon.

Table 5 reveals that the forecasting power of the trend deviation term is concentrated at 
much shorter horizons. The third panel of shows that the predictive power of $\widehat{c a y}_{t}$ is humped shaped and peaks around one year; using this single variable alone achieves an $\bar{R}^{2}$ of 0.21 for excess returns over a 5 quarter horizon (not reported in the table).

When we include the stochastically detrended short rate, the dividend yield, the payout ratio and the trend deviation together as predictive variables, the $\bar{R}^{2}$ statistic at each forecasting horizon is close to the sum of the $\bar{R}^{2}$ statistics from the second and third panels. By including all four variables, the model now has forecasting power for returns at every horizon we consider, although the total fraction of variation in long horizon returns that is predicted remains above that of short horizon returns. These results underscore the finding that $\widehat{c a y}_{t}$ is the best univariate predictor of returns at short to intermediate horizons: at a 4 quarter horizon, the $\bar{R}^{2}$ from the regression using just $\widehat{c a y}_{t}$ is almost as large as that in the last panel of Table 5 obtained using all four variables.

How can we understand the relative strengths and weaknesses of $\widehat{c a y}_{t}$ and $d_{t}-p_{t}$ at forecasting returns over different horizons? One way to understand these differences is to note that the discount rates in (12) and (13) differ. In (13) $\rho_{a} \equiv 1 /(1-\exp (\overline{d-p}))$, where $\exp (\overline{d-p})$ is average ratio of dividends to prices, about 0.99 at a quarterly rate. ${ }^{25}$ By contrast, the discount rate, $\rho_{w}$, in (12) is slightly smaller, equal to about 0.97 as suggested by using our estimates of $\omega$ and sample mean ratios of $C / A$ and $C / Y$. Accordingly, changes in expected returns in the far future are discounted a bit more in the equation for $c a y_{t}$ than in the equation for $d_{t}-p_{t}$. Thus the dividend-price ratio is a better proxy for returns into the distant future than is the trend deviation term. Even abstracting from this difference in discount rates, however, differences in the forecasting power at different horizons may arise if the time series process for expected asset returns is more persistent than that for expected returns to human capital. In this case, $\widehat{c a y}$ would be less persistent than the dividend-price ratio, consistent with the evidence in Table 2, and would therefore explain a smaller fraction of the variation in expected returns at longer horizons than would the dividend yield. ${ }^{26}$

\footnotetext{
${ }^{25}$ These estimates come from Campbell, Lo and MacKinlay (1997).

${ }^{26}$ Campbell, Lo and MacKinlay (1997, Ch. 7) develop a simple example to illustrate the effect of persistent
} in expected returns on the forecastability of returns as the horizon increases. 


\subsection{Vector Autoregressions}

The single equation regressions presented in the last section provide a simple way to summarize the marginal predictive power of each forecasting variable, as well as the overall explanatory power of the forecasting equation. An alternative approach uses VARs to impute long-horizon statistics rather than estimating them directly. One advantage of this approach is that it avoids small sample biases that may occur in single equation techniques and that can be especially pronounced when the horizon is large relative to the sample size. ${ }^{27}$ In this section, we investigate the predictive power of the full VAR counterpart to the equations analyzed previously for long-horizon returns. The methodology for measuring long-horizon statistics by estimating a VAR has been covered by Campbell (1991), Hodrick (1992), and Kandel and Stambaugh (1989), and we refer the reader to those articles for a description of the approach.

For each return horizon we consider, we calculate an implied $R^{2}$ using the coefficient estimates of the VAR and the estimated covariance matrix of the VAR residuals. Table 6 gives the results from estimating two first-order VARs. The first system is a four variable VAR that includes the excess return on the $\mathrm{S} \& \mathrm{P}$ Composite Index, the relative bill rate, the $\log$ dividend-price ratio and the log dividend-earnings ratio. The second is a five variable VAR that adds detrended asset wealth to this system. The table reports the coefficient estimates from each VAR in the top and bottom panels along with Newey-West corrected $t$-statistics in parentheses. The bottom row of each panel gives the implied $R^{2}$ of a regression of long-horizon excess returns on the other variables in the system.

The coefficient estimates from the five variable VAR with $\widehat{c a y}_{t}$ indicate that there are some cross-effects between the trend deviation and the log dividend-price ratio: each variables enter significantly in the other's equation. Nevertheless its clear that the relatively high persistence of these variables accounts for most of next quarter's variation in each of them; a univariate autoregression describes the dynamics of $d_{t}-p_{t}$ and $\widehat{c a y}_{t}$ almost as well as the VAR does.

\footnotetext{
${ }^{27}$ Hodrick (1992) presents Monte Carlo evidence that the VAR alternative supplies unbiased measurements of long-horizon implied statistics.
} 
The predictive power of the full VAR for long-horizon returns is similar to that obtained using the single-equation, direct-estimation approach presented in Table 5. In general, the VAR $R^{2}$ statistics from the model which includes $\widehat{c a y}_{t}$ are considerably higher than those from the model which excludes this variable. At a horizon of 2 quarters, adding $\widehat{c a y}_{t}$ to the VAR increases the implied $R^{2}$ by $9 \%$, raising it from $13 \%$ to $22 \%$; at a horizon of 3 quarters the implied $R^{2}$ is doubled by adding $\widehat{c a y}_{t}$, rising from $15 \%$ to $30 \%$, and at a horizon of two years, the VAR with $\widehat{c a y}_{t}$ explains $35 \%$ of the variation in excess returns compared to $23 \%$ excluding this variable.

As we extend the horizon out further, including deviations from the trend in assets continues to improve forecasts, but the incremental predictive power gradually declines and becomes quite small at horizons as long as six years. Nevertheless, the explained variance of the compound six year return is $44 \%$, primarily due to the long-horizon forecasting power of the log dividend-price ratio. Thus the VAR results underscore the conclusions drawn previously, that a substantial fraction of the variation in excess returns at horizons ranging from 1 quarter to over 5 years may be explained by combining information on deviation from the shared trend among consumption, assets and labor income, with information on financial variables such as the dividend yield, the dividend payout ratio, and the relative bill rate.

\section{$7 \quad$ Out-of-Sample Forecasting}

The results above show that $\widehat{c a y}_{t}$ has considerable forecasting power for excess stock returns over short to intermediate horizons in-sample. This section presents some results on the power of $\widehat{c a y}_{t}$ to predict one-quarter ahead excess stock returns on the S\&P 500 Composite Index out-of-sample.

We evaluate the out-of-sample performance by comparing the mean-squared forecasting error from an unrestricted model which includes $\widehat{c a y}_{t}$ to a restricted, benchmark model which excludes this variable. Thus the unrestricted model nests the benchmark model. The exercise compares the one-step ahead forecasting performance of the benchmark with that of the benchmark augmented by $\widehat{c a y}_{t}$.

Before making this comparison, we must choose an appropriate benchmark. We do so by 
comparing the mean-squared forecasting error from a regression that included just the lagged excess return, $r_{t}-r_{f, t}$, as a predictive variable, to the mean-squared-error from regressions that included, in addition to this variable, the other control variables used in Table 4, that is the log dividend-price ratio, the log dividend-earnings ratio, the relative bill rate, and the term spread. Including these control variables did not improve, and often even deteriorated, the out-of-sample predictive power of a regression which used just the lagged dependent variable as a predictor. ${ }^{28}$ Accordingly, we take the more parsimonious model, using just the one-period lagged value of excess returns, as our benchmark. Results are presented from alternately augmenting the benchmark with either the one-period lagged value of detrended wealth, denoted $\widehat{c a y}_{t}$, or the two-period lagged value, denoted $\widehat{c a y}_{t-1}$.

Each model is first estimated using data from the fourth quarter of 1952 to the first quarter of 1968. We use recursive regressions to reestimate the model, adding one quarter at a time and calculating a series of one-step ahead forecasts. The forecasts are evaluated by comparing the mean-squared error from the set of one-step-ahead forecasts. At each step, the cointegrating parameters in $\widehat{c a y}_{t}$ are also reestimated. Since reestimation is likely to introduce sampling error in our estimates of these parameters during the early recursions, we present, for comparison, results based on a fixed cointegrating vector where the cointegrating parameters are set equal to their values estimated in the full sample. The latter case gives some idea of how the model would perform going forward if a practitioner used the existing estimates of $\beta_{a}$ and $\beta_{y}$ and faced a similar historical pattern of data.

Table 7 presents the results. In each case, the mean-squared forecasting error of the $\widehat{c a y}_{t}-$ augmented models is lower than that of the benchmark model. The bottom panel shows that fixing the cointegrating parameters at their full sample values further produces the greatest relative forecasting power of the $\widehat{c a y}_{t}$-augmented models. This suggests that reestimation of the cointegrating parameters induces some sampling error in the cointegrating parameter

\footnotetext{
${ }^{28}$ This finding is not surprising and reflects the classic trade-off between in-sample fit and out-of-sample forecast performance that commonly allows more parsimonious models to prevail in out-of-sample forecast comparisons. Most of the control variables used in Table 4 have a statistically insignificant impact on next quarter's excess return in our sample. An exception is the relative bill rate which-although statistically significant-adds very little to the $\bar{R}^{2}$ of the in-sample regression.
} 
estimates, making it harder for the augmented models to register an improvement over the benchmark. Nevertheless, including $\widehat{c a y}_{t}$ in the benchmark regression would have consistently improved forecasts even when the cointegrating vector is reestimated. Furthermore, using the one-period lagged value of the trend deviation term reduces the mean-squared error by more than a model which instead uses the two-period lagged value of this variable, but both models post improvements over the benchmark.

For each forecast comparison, we also ask whether the lower mean-squared error of the $\widehat{c a y}_{t}$-augmented forecasts is statistically significant. Table 7 provides two test statistics designed to determine whether the one-step ahead mean-squared forecasting error from a restricted, benchmark model is statistically different from an unrestricted model which includes additional predictive variables. Clark and McCracken (1999) derive the (non-standard) asymptotic distributions for a large number of statistical tests as applied to nested models and numerically generate the asymptotic critical values. The two tests we consider are those found by Clark and McCracken to have the best overall power and size properties. ${ }^{29}$ The first test, the CM test, is a modified Harvey, Leybourne and Newbold (1998) test statistic adapted to address potential small sample biases; the second is an out-of-sample $F$-type test (OOS F-test) developed in McCracken (1999). Both methods compare the mean-squared error of the unrestricted model with that of the restricted models, and each tests the null hypothesis that the restricted model's forecast "encompasses" all the relevant information for next period's value of the dependent variable against the alternative that the unrestricted model contains additional information. For each set of one-step ahead forecasts we consider, the CM and OOS F-Test both strongly reject the null that transitory wealth contains no additional information about future excess returns when the test statistics are compared against asymptotic critical values.

\footnotetext{
${ }^{29}$ Clark and McCracken use Monte Carlo simulations to evaluate the size and power of a battery of equal forecast accuracy and encompassing tests. They find that size distortions in the CM and OOS F-test, as well as in in-sample Granger causality tests, are small. They also show that popular test statistics such as the Diebold and Mariano (1995) and Harvey, Leybourne and Newbold (1998) fail to converge to the standard normal distribution when the models being compared are nested rather than non-nested. Clark (forthcoming) studies the finite-sample properties of these test statistics.
} 


\section{Conclusion}

The last decade has brought forth an outpouring of research suggesting the existence of time-variation in expected asset returns. It is now widely accepted that excess returns are predictable by variables such as dividend-price ratios, earnings-price ratios, dividendearnings ratios and an assortment of other financial indicators. For the most part, these financial variables have been successful at predicting long horizon returns, but less successful at predicting returns at short horizons.

In this paper, we investigate a broad framework for optimal consumption which implies consumption, labor income and asset wealth are cointegrated, and that deviations from this shared trend summarize investors' expectations of future returns on the market portfolio. We show that these deviations from trend primarily forecast future movements in asset wealth, rather than future movements in consumption or labor income, implying that consumption and labor income can be used to detrend household asset wealth.

To develop the empirical implications of this framework, we investigate the power of these deviations from trend in assets for forecasting asset returns. We find that trend deviations in household net worth contain important predictive elements for stock market returns over short and intermediate horizons. Indeed, of the popular forecasting variables explored to date, we find that this variable is the best univariate predictor of stock returns for horizons up to one year. Combining observations on these trend deviations with those on the log dividend-price ratio and the log dividend-earnings ratio reveals that stock returns exhibit substantial forecastability at horizons ranging from short to long.

These empirical results can be understood using the optimal consumption framework we investigate. The model we present directly connects consumer behavior with future stock market returns: consumers tend to smooth out anticipated, transitory movements in tomorrow's returns by factoring them into consumption today. When wealth is temporarily higher than its long term trend with consumption and labor income, investors must be expecting returns on the market portfolio to fall and are holding consumption temporarily below its trend relationship with assets and income in anticipation of lower returns. Accordingly, deviations from the shared trend in consumption, labor income and wealth should be a good proxy 
for market expectations of future asset returns, as long as expectations of future returns to human capital are not too variable.

We find that the deviation in the shared trend among consumption, labor income and wealth forecasts excess stock returns over a risk-free rate just as well as it forecasts real stock returns. This feature of the data suggests that expected excess returns, or risk premia, vary over time, a conclusion that has been drawn previously from evidence that long-horizon returns are predictable by variables such as the dividend-price ratio. Yet the dividend-price ratio provides only indirect evidence that risk premia vary at cyclical frequencies, since its forecasting power is concentrated at longer horizons. By contrast, we find that transitory asset wealth, as measured by the deviation in wealth from its shared trend with consumption and labor income, has strong predictive power for excess stock returns at business cycle frequencies, providing direct evidence that risk premia vary countercyclically.

An important policy implication of our results is that large swings in financial assets need not be associated with large subsequent movements in consumption. Recently, this issue has become one of pressing importance as fears rise that substantial market swings will cause consumer spending to fluctuate sharply. The model considered in this paper suggests that the real economy maybe less vulnerable to transitory movements in asset values than many analysts presume: with consumption well below its traditional ratio to asset wealth and labor income, the model implies that households have already factored the expectation of lower returns in to today's consumption and will therefore not need to make large adjustments tomorrow.

An obvious next step for research is to link these findings on the time series behavior of excess returns to the large literature on cross-sectional asset pricing. In an intertemporal setting, cross-sectional asset pricing models imply that the risk of an asset can be measured by the innovation covariance of the asset's return with the current market return, and by its covariance with revisions in expected future returns, where the latter is often called the "hedging" component of asset demand. To date, however, researchers have not found an important intertemporal hedging component in the demand for assets (for example, Campbell 1996; Hodrick, Ng, and Sengmueller 1998). This could be because the intertemporal component of asset demand is not important, or because researchers have not yet found an 
adequate proxy for expected future returns to the market portfolio.

Moreover, a number of papers have emphasized the importance accounting for the return to human capital in the market return (Roll 1977; Campbell 1996). Since human capital is not observable, assumptions have to be made in obtaining a tractable proxy. For example, Campbell (1996) assumes that the return to human capital may be expressed as the expected future value of labor income growth discounted by the return on financial wealth. While these and other assumptions seem plausible, there is no way of testing their validity.

The economic variable explored in this paper provides a fresh opportunity to investigate the determinants of asset risk. The predictive power of deviations from trend wealth may be obtained under the relatively unrestrictive assumption that the nonstationary component of human wealth is well captured by labor income itself. The consumption framework investigated here implies that investors' own behavior, as captured by deviations in household wealth from its trend relationship with consumption and labor income, should reveal expectations of future returns to both human and nonhuman capital, providing a unique proxy of expected returns to the market portfolio. 


\section{Appendix A: Tests for Cointegration}

This appendix describes procedures we use to test for cointegration among consumption, labor income and household wealth. We furnish the output from these tests in Tables A.1-A.4 at the end of the text.

The consumption data are for nondurables and services excluding shoes and clothing. The nonhuman wealth data is the household net worth series provided by the Board of Governors of the Federal Reserve. Labor income is defined as wages and salaries plus transfer payments plus other labor income minus personal contributions for social insurance minus taxes. Taxes are defined as (wages and salaries)/ (wages and salaries + proprietors income with IVA and Ccadj + rental income + personal dividends + personal interest income $))^{*}($ personal tax and non tax payments), where IVA is inventory evaluation and Ccadj is capital consumption adjustments. Consumption is in 1992 chain weighted dollars; wealth and labor income are deflated by the PCE chain-type price deflator.

We report the results of two types of cointegration tests: residual based tests designed to distinguish a system without cointegration from a system with at least one cointegrating relationship, and tests for cointegrating rank designed to estimate the number of cointegrating relationships. The former requires that each individual variable pass a unit root test and are conditional on this pretesting procedure. Table A.1 presents Dickey-Fuller tests for the presence of a unit root in $c, y$, and $a$, over several autoregressive structures. The procedure tests the null hypothesis of a unit root against the alternative hypothesis that the series is stationary around a trend. The test statistics fall within the 95 percent confidence region and are therefore consistent with the hypothesis of a unit root in those series.

Table A.2 reports test statistics corresponding to the Phillips-Ouliaris (1990) residual based cointegration tests. This test is designed to distinguish a system without cointegration from a system with at least one cointegrating relationship. The approach applies the augmented Dickey-Fuller unit root test to the residuals of from a regression of consumption on labor income and household wealth. The table shows both the Dickey-Fuller t-statistic and the relevant 5 and 10 percent critical values. ${ }^{30}$ In the model without a deterministic

\footnotetext{
${ }^{30}$ Phillips and Ouliaris (1990) tabulate critical values for the augmented Dickey-Fuller t test applied to
} 
trend, the hypothesis of no cointegration is rejected at the 5 percent level by the augmented Dickey-Fuller test with 1, 2 or 3 lags, but is not rejected by the test with 4 lags. We applied the data dependent procedure suggested in Campbell and Perron (1991) for choosing the appropriate lag length in an augmented Dickey-Fuller test. This procedure suggested that the appropriate lag length was one, implying that test results favoring cointegration should be accepted.

Next we consider testing procedures suggested by Johansen $(1988,1991)$ that allow the researcher to estimate the number of cointegrating relationships. This procedure presumes a $p$-dimensional vector autoregressive model with $\mathrm{k}$ lags, where $p$ corresponds to the number of stochastic variables among which the investigator wishes to test for cointegration. For our application, $p=3$. The Johansen procedure provides two tests for cointegration: under the null hypothesis, $H_{0}$, that there are exactly $\mathrm{r}$ cointegrating relations, the 'Trace' statistic supplies a likelihood ratio test of $H_{0}$ against the alternative, $H_{A}$, that there are $p$ cointegrating relations, where $p$ is the total number of variables in the model. A second approach uses the 'L-max' statistic to test the null hypothesis of $r$ cointegrating relations against the alternative of $r+1$ cointegrating relations. The test procedure depends the number of lags assumed in the vector autoregressive structure. The table presents the test results obtained under a number of lag assumptions. The same effective sample (1954:1 to 1998:3) was used in estimating the model under each lag assumption.

The critical values obtained using the Johansen approach also depend on the trend characteristics of the data. We present results allowing for linear trends in data, but assuming that the cointegrating relation has only a constant (Table A.3). See Johansen (1988, 1991) for a more detailed discussion of these trend assumptions. ${ }^{31}$ The Table also reports the 90 residuals of a cointegrating equation with up to five variables.

${ }^{31}$ In choosing the appropriate trend model for our data, we were guided by both theoretical considerations and statistical criteria. Theoretical considerations imply that the long-run equilibrium relationship between consumption, labor income and wealth do not have deterministic trends, although each individual data series may have deterministic trends. Moreover, statistical criteria suggested that modeling a trend in the cointegrating relation was not appropriate: the normalized cointegrating equation under this assumption did not correspond to any reasonable hypothesis about the long-run relationship among these variables. For example, with trends specified in the cointegrating relationship, the parameters of the cointegrating vector 
percent critical values for these statistics. ${ }^{32}$

The Johansen L-max test results establish strong evidence of a single cointegrating relation among log consumption, log labor income, and the log of household wealth. Table A.4 shows that, for every lag specification we consider, we may reject the null of no cointegration against the alternative of one cointegrating vector. In addition, we cannot reject the null hypothesis of one cointegrating relationship against the alternative of two or three. While the evidence in favor of cointegration is somewhat weaker according to the Trace statistic (we cannot reject the null of no cointegration against the alternative of 3 cointegrating relations), this evidence is contradicted by the unit root tests which suggest that each variable contains a unit root. Moreover, according to the Trace statistic, we may not reject the null of one (or two) cointegrating relations against the alternative of three.

were often negative, at odds with any sensible model of consumer behavior.

${ }^{32}$ The critical values are based on calculations made by Johansen and Nielsen (1993). 


\section{References}

[1] Blinder, Alan S., and Angus Deaton. 1985. "The Time Series Consumption Function Revisited." Brookings Papers on Economic Activity. 0 no.2: 465-511.

[2] Campbell, John Y. 1987. "Stock Returns and the Term Structure." Journal of Financial Economics. 18: 373-99.

[3] Campbell, John Y. 1987. "Does Saving Anticipate Declining Future Labor Income? An Alternate Test of the Permanent Income Hypothesis." Econometrica. 55 no. 2: 1249-73.

[4] Campbell, John Y., and R. Shiller. 1988. "The Dividend-Price Ratio and Expectations of Future Dividends and Discount Factors." Review of Financial Studies. 1: 195-227.

[5] Campbell, John Y., and Gregory Mankiw. 1989. "Consumption, Income and Interest Rates: Reinterpreting the Time Series Evidence." in Olivier J. Blanchard and Stanley Fischer (Eds.), NBER Macroeconomics Annual Cambridge, Mass, MIT Press, 185-216.

[6] Campbell, John Y. 1991. "A Variance Decomposition for Stock Returns." Economic Journal. 101: 157-179.

[7] Campbell, John Y., and Pierre Perron. 1991. "Pitfalls and Opportunities: What Macroeconomists Should Know about Unit Roots." NBER Macroeconomics Annual 141-201.

[8] Campbell, John Y. 1993. "Intertemporal Asset Pricing without Consumption Data." American Economic Review. 83: 487-512.

[9] Campbell, John Y. 1996. "Understanding Risk and Return." Journal of Political Economy. 104: 298-345.

[10] Campbell John Y., A. Lo, and C. MacKinlay. 1997. "The Econometrics of Financial Markets." Princeton University Press.

[11] Campbell, John Y., and John H. Cochrane. 1999. "By Force of Habit: A ConsumptionBased Explanation of Aggregate Stock Market Behavior." Journal of Political Economy 107(April): 205-51. 
[12] Clark, Todd and Michael McCracken. 1999. "Granger Causality and Tests of Equal Forecast Accuracy and Encompassing." Manuscript, Federal Reserve Bank of Kansas City.

[13] Clark, Todd. Forthcoming. "Finite-Sample Properties of Tests for Equal Forecast Accuracy." Journal of Forecasting.

[14] Cochrane, John H. 1991a. "Volatility Tests and Efficient Markets: A Review Essay." Journal of Monetary Economics 127: 463-85.

[15] Cochrane, John H. 1991b. "Explaining the Variance of Price-Dividend Ratios." Review of Financial Studies 15: 243-80.

[16] Cochrane, John H. 1994. "Permanent and Transitory Components of GNP and Stock Prices." Quarterly Journal of Economics. 109 no.1: 241-65.

[17] Cumby, R., and D. Modest. 1987. "Testing for Market Timing Ability: A Framework for Forecast Evaluation." Journal of Finance. 19: 169-190.

[18] Diebold, Francis, and Roberto Mariano. 1995. "Comparing Predictive Accuracy." Journal of Business and Economic Statistics. 12, no.3: 253-63.

[19] Epstein, L., and S. Zin. 1989. "Substitution, Risk Aversion, and the Temporal Behavior of Consumption and Asset Returns: A Theoretical Framework." Econometrica. 57: 937968.

[20] Fama, F., and K. French. 1988. "Dividend Yields and Expected Stock Returns." Journal of Financial Economics. 22: 3-27.

[21] Fama, F., and K. French. 1989. "Business Conditions and Expected Returns on Stocks and Bonds." Journal of Financial Economics. 25: 23-49.

[22] Flavin, Marjorie. 1981. "The Adjustment of Consumption to Changing Expectations about Future Income." Journal of Political Economy. 89:974-1009. 
[23] Flood, Robert. P., Robert J. Hodrick, and Paul Kaplan. 1986. "An Evaluation of Recent Evidence on Stock Market Bubbles." Northwestern University. Working Paper. Reprinted in Peter M. Garber and Robert P. Flood. 1994. "Speculative Bubbles, Speculative Attacks, and Policy Switching." Cambridge: MIT Press. 105-133

[24] Galí, Jordi. 1990. "Finite Horizons, Life-Cycle Savings, and Time-Series Evidence on Consumption." Journal of Monetary Economics 26 no.3: 433-52.

[25] Hall, R. 1988. "Stochastic Implications of the Life-Cycle Permanent Income Hypothesis: Theory and Evidence." Journal of Political Economy. 86: 971-87.

[26] Hall, R. 1988. "Intertemporal Substitution in Consumption." Journal of Political Economy. 96: 221-273.

[27] Harvey, David, Stephen Leybourne, and Paul Newbold. 1998. "Tests for Forecast Encompassing." Journal of Business and Economic Statistics 16, no.2: 254-59.

[28] Hodrick, R. 1992. "Dividend Yields and Expected Stock Returns: Alternative Procedures for Inference and Measurement." Review of Financial Studies. 5: 357-386.

[29] Hodrick, R., D. Ng, and P. Sengmueller. 1998. "An International Dynamic Asset Pricing Model." Unpublished paper, Columbia University.

[30] Johansen, Soren. 1988. "Statistical Analysis of Cointegrating Vectors." Journal of Economic Dynamics and Control. 12 no. 2/3: 231-54.

[31] Johansen, Soren. 1991. "Estimation and Hypothesis Testing of Cointegration Vectors in Gaussian Vector Autoregressive Models." Econometrica 56 no. 6: 1551-80.

[32] Johansen, Soren and B. Nielsen 1993. "Asymptotics for Cointegrating Rank Tests in the Presence of Intervention Dummies-Manual for the Simulation Program DISCO." Manuscript, Institute for Mathematical Statistics, University of Copenhagen.

[33] Kandel, S., and R. Stambaugh. 1989. "Modelling Expected Stock Returns for Long and Short Horizons." Rodney L. White Center, Wharton School, University of Pennsylvania, Working Paper 42-88. 
[34] Lamont, Owen. 1998. "Earnings and Expected Returns." Journal of Finance. Vol. LIII no.5: 1563-1587

[35] Ludvigson, Sydney and Charles Steindel. Forthcoming. "How Important is the Stock Market Effect on Consumption?" FRBNY Economic Policy Review.

[36] McCracken, Michael. 1999. "Asymptotics for Out-of-Sample Tests of Causality." Manuscript, Louisiana State University.

[37] Merton, R. 1973. "An Intertemporal Capital Asset Pricing Model." Econometrica. 41: $867-887$.

[38] Phillips, P., and S. Ouliaris. 1990. “Asymptotic Properties of Residual Based Tests for Cointegration." Econometrica 58 no. 1: 165-93.

[39] Roll, R. 1977. "A Critique of the Asset Pricing Theory's Tests: Part I." Journal of Financial Economics. 4: 129-176.

[40] Shiller, Robert. 1984. "Stock Prices and Social Dynamics." Brooking Papers on Economic Activity. 2: 457-498.

[41] Shiller, Robert 1989. Market Volatility Cambridge, MA: MIT Press.

[42] Stock, James H. 1987. "Asymptotic Properties of Least Squares Estimators of Cointegrating Vectors." Econometrica. 55: 113-144.

[43] Stock, James H., and Mark Watson. 1993. "A Simple Estimator of Cointegrating Vectors in Higher Order Integrated Systems." Econometrica 61: 783-820. 


\section{Table 1}

\section{Estimates From a Cointegrated VAR}

Sum of regression coefficients of column variable on row variable

\begin{tabular}{cccc}
\hline & $\Delta c_{t}$ & $\Delta a_{t}$ & $\Delta y_{t}$ \\
\hline$\Delta c_{t-i, i=1, . .2}$ & $\mathbf{0 . 2 9 6}$ & 0.208 & $\mathbf{0 . 5 7 5}$ \\
$(t$-stat $)$ & $(2.232)$ & $(0.581)$ & $(2.130)$ \\
$\Delta a_{t-i, i=1, . .2}$ & 0.019 & 0.177 & 0.081 \\
$(t$-stat $)$ & $(0.706)$ & $(1.601)$ & $(1.685)$ \\
$\Delta y_{t-i, i=1, . .2}$ & 0.074 & 0.239 & -0.060 \\
$(t$-stat $)$ & $(0.821)$ & $(1.258)$ & $(-0.325)$ \\
$\widehat{c a y}_{t-1}$ & -0.015 & $\mathbf{0 . 4 4 5}$ & 0.100 \\
$(t$-stat $)$ & $(-0.275)$ & $(2.885)$ & $(1.754)$ \\
$\bar{R}^{2}$ & 0.12 & 0.14 & 0.05 \\
\hline \hline
\end{tabular}

Notes: Sample period is 1952:4 to 1998:3. Entries in the top panel report the sum of the coefficients on the lags of variables; beneath each coefficient sum is the Newey-West corrected $t$-statistic for the sum. Significant coefficients at the $5 \%$ level are highlighted in bold face. $\widehat{c a y}_{t}$ is $c_{t}-\widehat{\beta}_{a} a_{t}-\widehat{\beta}_{y} y_{t}$, the estimated trend deviation. 


\section{Table 2}

\section{Summary Statistics}

\begin{tabular}{cccccc}
\hline \hline \multicolumn{7}{c}{$r_{t}-r_{f, t}$} & $d_{t}-p_{t}$ & $d_{t}-e_{t}$ & $R R E L_{t}$ & $\widehat{\text { cay }}_{t}$ \\
\hline \hline \multicolumn{6}{c}{ Correlation Matrix } \\
\hline$r_{t}-r_{f}$ & 1.00 & -0.15 & 0.08 & -0.30 & 0.28 \\
$d_{t}-p_{t}$ & & 1.00 & 0.01 & -0.01 & 0.43 \\
$d_{t}-e_{t}$ & & & 1.00 & -0.46 & 0.15 \\
$R R E L_{t}$ & & & & 1.00 & -0.23 \\
$\widehat{c a y}_{t}$ & & & & & 1.00 \\
\hline \multicolumn{7}{c}{ Univariate Summary Statistics } \\
\hline Mean & 0.016 & -3.358 & 0.680 & 0.000 & 0.593 \\
Standard Error & 0.077 & 0.277 & 0.199 & 0.011 & 0.011 \\
Autocorrelation & 0.12 & 0.93 & 0.70 & 0.71 & 0.79 \\
\hline \hline
\end{tabular}

Notes: $r_{t}-r_{f, t}$ is quarterly log excess returns on the $\mathrm{S} \& \mathrm{P}$ Composite index; $d_{t}-p_{t}$ is the $\log$ dividend yield; $d_{t}-e_{t}$ is the log dividend payout ratio; $R R E L_{t}$ is the relative bill rate; $\widehat{c a y}_{t}$ is $c_{t}-\widehat{\beta}_{a} a_{t}-\widehat{\beta}_{y} y_{t}$, the estimated trend deviation. The statistics are computed for the largest common span of available data for all the variables. Sample period is 1952:4 to 1998:3. 


\section{Table 3}

Forecasting Quarterly Stock Returns

\begin{tabular}{|c|c|c|c|c|c|c|}
\hline Dependent Variable & Index & $\begin{array}{l}\text { Constant } \\
(t \text {-stat })\end{array}$ & $\begin{array}{c}r_{t} \\
(t \text {-stat })\end{array}$ & $\begin{array}{c}\widehat{c a y}_{t} \\
(t \text {-stat })\end{array}$ & $\begin{array}{l}\widehat{c a y}_{t-1} \\
(t \text {-stat })\end{array}$ & $\bar{R}^{2}$ \\
\hline \multirow[t]{8}{*}{$r_{t+1}$} & S\&P 500 & $\begin{array}{c}\mathbf{0 . 0 1 7} \\
(3.131)\end{array}$ & $\begin{array}{l}\mathbf{0 . 1 3 6} \\
(2.221)\end{array}$ & & \multirow{8}{*}{$\begin{array}{c}\mathbf{1 . 6 6 2} \\
(2.677)\end{array}$} & 0.01 \\
\hline & & 0.029 & & 2.220 & & 0.09 \\
\hline & & $(4.672)$ & & $(3.024)$ & & \\
\hline & & 0.026 & 0.062 & 2.109 & & 0.09 \\
\hline & & $(4.645)$ & $(0.981)$ & $(2.806)$ & & \\
\hline & & $\begin{array}{c}\mathbf{0 . 0 2 4} \\
(5.188)\end{array}$ & $\begin{array}{c}0.075 \\
(1.312)\end{array}$ & & & 0.06 \\
\hline & CRSP-VW & $\begin{array}{c}\mathbf{0 . 0 2 8} \\
(4.889)\end{array}$ & $\begin{array}{c}-0.007 \\
(-0.157)\end{array}$ & $\begin{array}{c}\mathbf{2 . 5 1 3} \\
(4.754)\end{array}$ & & 0.10 \\
\hline & small stocks & $\begin{array}{c}\mathbf{0 . 0 4 0} \\
(5.484)\end{array}$ & $\begin{array}{c}-0.099 \\
(-1.356)\end{array}$ & $\begin{array}{c}\mathbf{3 . 5 1 2} \\
(4.690)\end{array}$ & & 0.09 \\
\hline Dependent Variable & Index & $\begin{array}{c}\text { Constant } \\
(t \text {-stat })\end{array}$ & $\begin{array}{c}r_{t}-r_{f, t} \\
(t \text {-stat })\end{array}$ & $\begin{array}{c}\widehat{c a y}_{t} \\
(t \text {-stat })\end{array}$ & $\begin{array}{l}\widehat{c a y}_{t-1} \\
(t \text {-stat })\end{array}$ & $\bar{R}^{2}$ \\
\hline \multirow[t]{8}{*}{$r_{t+1}-r_{f, t+1}$} & S\&P 500 & $\begin{array}{c}\mathbf{0 . 0 1 4} \\
(2.952)\end{array}$ & $\begin{array}{l}\mathbf{0 . 1 1 9} \\
(1.976)\end{array}$ & & \multirow{8}{*}{$\begin{array}{c}\mathbf{1 . 6 2 1} \\
(2.902)\end{array}$} & 0.00 \\
\hline & & 0.024 & & 2.165 & & 0.09 \\
\hline & & $(4.328)$ & & $(3.226)$ & & \\
\hline & & 0.023 & 0.043 & 2.089 & & 0.09 \\
\hline & & $(4.345)$ & $(0.707)$ & $(2.988)$ & & \\
\hline & & $\begin{array}{c}\mathbf{0 . 0 2 1} \\
(4.945)\end{array}$ & $\begin{array}{c}0.059 \\
(1.064)\end{array}$ & & & 0.05 \\
\hline & CRSP-VW & $\begin{array}{c}\mathbf{0 . 0 2 2} \\
(4.612)\end{array}$ & $\begin{array}{c}-0.038 \\
(-0.483)\end{array}$ & $\begin{array}{c}\mathbf{2 . 5 2 8} \\
(4.583)\end{array}$ & & 0.10 \\
\hline & small stocks & $\begin{array}{r}\mathbf{0 . 0 3 6} \\
(4.659) \\
\end{array}$ & $\begin{array}{c}-0.107 \\
(-1.361) \\
\end{array}$ & $\begin{array}{r}\mathbf{3 . 4 5 5} \\
(4.707) \\
\end{array}$ & & 0.09 \\
\hline
\end{tabular}


Notes for Table 3: Sample period is 1952:4 - 1998:3. Regressions of stock returns on lagged variables. $r_{t}$ is the quarterly log real return on the index named in the row heading; $r_{t+1}-r_{f, t+1}$, is quarterly $\log$ excess return on the index named in the row heading; $\widehat{c a y}_{t} \equiv c_{t}-\widehat{\beta}_{a} a_{t}-\widehat{\beta}_{y} y_{t}$, the estimated trend deviation in consumption. The index of small stocks is taken from Ibbotson and Associates. Newey-West corrected $t$-statistics appear in parentheses below the coefficient estimate. Significant coefficients at the $5 \%$ level are highlighted in bold face. 


\section{Table 4}

Forecasting Quarterly Excess Returns on the SEP 500 Index

\begin{tabular}{|c|c|c|c|c|c|c|c|c|c|}
\hline Sample & $\begin{array}{l}\text { Constant } \\
(t \text {-stat })\end{array}$ & $\begin{array}{l}d_{t}-p_{t} \\
(t \text {-stat })\end{array}$ & $\begin{array}{l}d_{t}-e_{t} \\
(t \text {-stat })\end{array}$ & $\begin{array}{c}\widehat{c a y}_{t} \\
(t \text {-stat })\end{array}$ & $\begin{array}{c}r_{t}-r_{f, t} \\
(t \text {-stat })\end{array}$ & $\begin{array}{c}R R E L_{t} \\
(t \text {-stat })\end{array}$ & $\begin{array}{l}T R M_{t} \\
(\text { t-stat })\end{array}$ & $\begin{array}{c}D E F_{t} \\
(t \text {-stat) }\end{array}$ & $\bar{R}^{2}$ \\
\hline \multirow[t]{4}{*}{ 1952:4-1998:3 } & $\begin{array}{c}0.100 \\
(1.157)\end{array}$ & $\begin{array}{c}0.025 \\
(0.965)\end{array}$ & & & & & & & 0.00 \\
\hline & $\begin{array}{c}-0.012 \\
(-0.135)\end{array}$ & $\begin{array}{c}-0.011 \\
(-0.404)\end{array}$ & & $\begin{array}{c}\mathbf{2 . 2 7 4} \\
(4.131)\end{array}$ & & & & & 0.09 \\
\hline & $\begin{array}{c}0.058 \\
(0.656)\end{array}$ & $\begin{array}{c}0.025 \\
(0.805)\end{array}$ & $\begin{array}{c}0.060 \\
(1.531)\end{array}$ & & & & & & 0.02 \\
\hline & $\begin{array}{c}-0.036 \\
(-0.398)\end{array}$ & $\begin{array}{c}-0.009 \\
(-0.267)\end{array}$ & $\begin{array}{c}0.043 \\
(1.289)\end{array}$ & $\begin{array}{c}\mathbf{2 . 1 4 5} \\
(4.182)\end{array}$ & & & & & 0.09 \\
\hline 1953:2-1998:3 & $\begin{array}{c}0.038 \\
(0.278)\end{array}$ & $\begin{array}{c}0.004 \\
(0.095)\end{array}$ & $\begin{array}{c}0.011 \\
(0.270)\end{array}$ & $\begin{array}{l}\mathbf{1 . 9 0 6} \\
(3.197)\end{array}$ & $\begin{array}{c}-0.004 \\
(-0.065)\end{array}$ & $\begin{array}{l}\mathbf{- 1 . 3 7 7} \\
(-2.443)\end{array}$ & $\begin{array}{c}-0.082 \\
(-0.125)\end{array}$ & $\begin{array}{l}-0.883 \\
(-0.543)\end{array}$ & 0.10 \\
\hline \multirow[t]{3}{*}{ 1952:4-1994:4 } & $\begin{array}{l}\mathbf{0 . 2 5 7} \\
(2.768)\end{array}$ & $\begin{array}{c}\mathbf{0 . 1 0 0} \\
(3.257)\end{array}$ & $\begin{array}{c}\mathbf{0 . 1 2 6} \\
(3.055)\end{array}$ & & & & & & 0.11 \\
\hline & $\begin{array}{l}\mathbf{0 . 0 2 1} \\
(3.657)\end{array}$ & & & $\begin{array}{l}\mathbf{2 . 6 4 2} \\
(4.488)\end{array}$ & & & & & 0.11 \\
\hline & $\begin{array}{l}\mathbf{0 . 1 7 5} \\
(2.379)\end{array}$ & $\begin{array}{c}\mathbf{0 . 0 7 0} \\
(2.910)\end{array}$ & $\begin{array}{c}\mathbf{0 . 1 0 5} \\
(3.039)\end{array}$ & $\begin{array}{l}\mathbf{2 . 0 8 2} \\
(3.952)\end{array}$ & & & & & 0.17 \\
\hline
\end{tabular}

Notes: $O L S$ regressions of excess stock returns on lagged variables named at the head of a column. The dependent variable, $r_{t+1}-r_{f, t+1}$, is quarterly log excess returns on the S\&P Composite index; $d_{t}-p_{t}$ is the $\log$ dividend yield; $d_{t}-e_{t}$ is the log dividend payout ratio; $R R E L_{t}$ is the relative bill rate; $T R M_{t}$ is the term spread, the difference between the 10 year Treasury bond yield and the 3 month Treasury bond yield; $D E F_{t}$ is the BAA Corporate Bond rate minus the AAA Corporate Bond rate; $\widehat{c a y}_{t}$ is $c_{t}-\widehat{\beta}_{a} a_{t}-\widehat{\beta}_{y} y_{t}$, the estimated trend deviation. Newey-West corrected tstatistics appear in parentheses below the coefficient estimate. Significant coefficients at the 5\% level are highlighted in bold face. The regression using the term and default spreads is run over the largest common sample available for all the variables in the equation. 


\section{Table 5}

Long-Horizon Regressions 1952:4-1998:3

\begin{tabular}{|c|c|c|c|c|c|c|c|c|}
\hline \multirow[t]{2}{*}{ Regressors } & \multicolumn{8}{|c|}{ Forecast Horizon $H$} \\
\hline & 1 & 2 & 3 & 4 & 8 & 12 & 16 & 24 \\
\hline \multirow[t]{2}{*}{$d_{t}-p_{t}$} & $\begin{array}{c}0.02 \\
(0.97)\end{array}$ & $\begin{array}{c}0.05 \\
(1.01)\end{array}$ & $\begin{array}{c}0.09 \\
(1.01)\end{array}$ & $\begin{array}{c}0.13 \\
(1.12)\end{array}$ & $\begin{array}{c}0.28 \\
(1.25)\end{array}$ & $\begin{array}{c}0.36 \\
(1.46)\end{array}$ & $\begin{array}{c}0.43 \\
(1.70)\end{array}$ & $\begin{array}{c}\mathbf{0 . 9 9} \\
(3.76)\end{array}$ \\
\hline & {$[0.00]$} & {$[0.01]$} & {$[0.02]$} & {$[0.03]$} & {$[0.08]$} & {$[0.09]$} & {$[0.11]$} & {$[0.30]$} \\
\hline$d_{t}-p_{t}$ & $\begin{array}{c}0.02 \\
(0.82)\end{array}$ & $\begin{array}{c}0.06 \\
(0.92)\end{array}$ & $\begin{array}{c}0.09 \\
(0.93)\end{array}$ & $\begin{array}{c}0.13 \\
(1.04)\end{array}$ & $\begin{array}{c}0.29 \\
(1.22)\end{array}$ & $\begin{array}{c}0.41 \\
(1.53)\end{array}$ & $\begin{array}{c}\mathbf{0 . 5 3} \\
(2.26)\end{array}$ & $\begin{array}{c}\mathbf{1 . 1 8} \\
(5.55)\end{array}$ \\
\hline \multirow[t]{2}{*}{$d_{t}-e_{t}$} & $\begin{array}{c}0.06 \\
(1.66)\end{array}$ & $\begin{array}{c}0.07 \\
(1.05)\end{array}$ & $\begin{array}{c}0.09 \\
(0.89)\end{array}$ & $\begin{array}{c}0.09 \\
(0.67)\end{array}$ & $\begin{array}{c}0.15 \\
(0.73)\end{array}$ & $\begin{array}{c}0.24 \\
(0.99)\end{array}$ & $\begin{array}{c}\mathbf{0 . 4 0} \\
(2.07)\end{array}$ & $\begin{array}{c}\mathbf{0 . 7 1} \\
(2.95)\end{array}$ \\
\hline & {$[0.02]$} & {$[0.02]$} & {$[0.03]$} & {$[0.04]$} & {$[0.09]$} & {$[0.12]$} & {$[0.17]$} & {$[0.41]$} \\
\hline \multirow[t]{2}{*}{$\widehat{c a y}_{t}$} & $\begin{array}{c}\mathbf{2 . 2 2} \\
(3.22)\end{array}$ & $\begin{array}{c}\mathbf{3 . 9 6} \\
(3.13)\end{array}$ & $\begin{array}{c}\mathbf{5 . 7 4} \\
(3.21)\end{array}$ & $\begin{array}{c}7.17 \\
(3.43)\end{array}$ & $\begin{array}{c}\mathbf{9 . 1 7} \\
(3.26)\end{array}$ & $\begin{array}{c}\mathbf{9 . 6 3} \\
(2.98)\end{array}$ & $\begin{array}{c}\mathbf{9 . 3 0} \\
(2.68)\end{array}$ & $\begin{array}{l}\mathbf{1 5 . 8 4} \\
(3.49)\end{array}$ \\
\hline & {$[0.09]$} & {$[0.12]$} & {$[0.17]$} & {$[0.19]$} & {$[0.16]$} & {$[0.14]$} & {$[0.11]$} & {$[0.18]$} \\
\hline$R R E L_{t}$ & $\begin{array}{l}\mathbf{- 1 . 1 7} \\
(-2.48)\end{array}$ & $\begin{array}{c}-2.35 \\
(-3.05)\end{array}$ & $\begin{array}{l}\mathbf{- 3 . 2 3} \\
(-2.91)\end{array}$ & $\begin{array}{l}\mathbf{- 3 . 8 2} \\
(-2.57)\end{array}$ & $\begin{array}{c}-0.27 \\
(-0.16)\end{array}$ & $\begin{array}{c}1.99 \\
(0.81)\end{array}$ & $\begin{array}{c}0.12 \\
(0.05)\end{array}$ & $\begin{array}{c}1.36 \\
(0.48)\end{array}$ \\
\hline$d_{t}-p_{t}$ & $\begin{array}{c}-0.00 \\
(-0.08)\end{array}$ & $\begin{array}{c}0.02 \\
(0.34)\end{array}$ & $\begin{array}{c}0.03 \\
(0.43)\end{array}$ & $\begin{array}{c}0.07 \\
(0.67)\end{array}$ & $\begin{array}{c}0.17 \\
(0.84)\end{array}$ & $\begin{array}{c}0.24 \\
(1.04)\end{array}$ & $\begin{array}{c}0.31 \\
(1.49)\end{array}$ & $\begin{array}{c}\mathbf{0 . 8 5} \\
(4.95)\end{array}$ \\
\hline$d_{t}-e_{t}$ & $\begin{array}{c}0.02 \\
(0.47)\end{array}$ & $\begin{array}{c}-0.02 \\
(-0.29)\end{array}$ & $\begin{array}{l}-0.03 \\
(-0.33)\end{array}$ & $\begin{array}{c}-0.05 \\
(-0.49)\end{array}$ & $\begin{array}{c}0.17 \\
(0.44)\end{array}$ & $\begin{array}{c}0.24 \\
(1.16)\end{array}$ & $\begin{array}{c}\mathbf{0 . 3 1} \\
(2.06)\end{array}$ & $\begin{array}{c}\mathbf{0 . 6 5} \\
(2.86)\end{array}$ \\
\hline \multirow[t]{2}{*}{$\widehat{c a y}_{t}$} & $\begin{array}{c}\mathbf{1 . 8 9} \\
(3.45)\end{array}$ & $\begin{array}{c}\mathbf{3 . 1 3} \\
(3.01)\end{array}$ & $\begin{array}{c}4.43 \\
(3.03)\end{array}$ & $\begin{array}{c}\mathbf{5 . 3 7} \\
(3.25)\end{array}$ & $\begin{array}{c}7.24 \\
(3.01)\end{array}$ & $\begin{array}{c}7.69 \\
(2.20)\end{array}$ & $\begin{array}{c}5.63 \\
(1.81)\end{array}$ & $\begin{array}{c}\mathbf{5 . 9 0} \\
(1.91)\end{array}$ \\
\hline & {$[0.11]$} & {$[0.15]$} & {$[0.21]$} & {$[0.23]$} & {$[0.18]$} & {$[0.19]$} & {$[0.18]$} & {$[0.42]$} \\
\hline
\end{tabular}

Notes: See next page. 
Notes for Table 5: Long-horizon regressions of excess returns on lagged variables using data from 1952:4-1998:3, OLS estimation. The dependent variable is the sum of $H$ log excess return of the $\mathrm{S} \& \mathrm{P}$ composite index, $r_{t+1}-r_{f, t+1}+\ldots+r_{t+H}-r_{f, t+H}$. The $H$-period excess return is regressed on one-period lagged values of the $\log$ dividend yield $d_{t}-p_{t}$, the dividend earnings ratio $d_{t}-e_{t}$, the deviations from trend $\widehat{c a y}_{t}=c_{t}-\widehat{\beta}_{a} a_{t}-\widehat{\beta}_{y} y_{t}$, and combinations thereof. For each regression, the table reports OLS estimates of the regressors, Newey-West corrected $t$-statistics in parentheses and adjusted $R^{2}$ statistics in square brackets. Significant coefficients at the $5 \%$ level are highlighted in bold. 


\section{Table 6}

Vector Autoregression of Excess Returns and Implied Long-Horizon $R^{2}$

\begin{tabular}{|c|c|c|c|c|c|c|c|}
\hline Dependent Variable & $\begin{array}{l}\text { Constant } \\
(t \text {-stat })\end{array}$ & $\begin{array}{c}r_{t}-r_{f, t} \\
(t \text {-stat })\end{array}$ & $\begin{array}{c}R R E L_{t} \\
(t \text {-stat })\end{array}$ & $\begin{array}{l}d_{t}-p_{t} \\
(t \text {-stat })\end{array}$ & $\begin{array}{l}d_{t}-e_{t} \\
(t \text {-stat })\end{array}$ & & $\bar{R}^{2}$ \\
\hline$r_{t+1}-r_{f, t+1}$ & $\begin{array}{c}0.000 \\
(0.035)\end{array}$ & $\begin{array}{c}0.078 \\
(1.287)\end{array}$ & $\begin{array}{l}\mathbf{- 1 . 3 0 9} \\
(-2.700)\end{array}$ & $\begin{array}{c}0.033 \\
(1.307)\end{array}$ & $\begin{array}{c}0.025 \\
(0.682)\end{array}$ & & 0.06 \\
\hline$R R E L_{t+1}$ & $\begin{array}{c}-0.000 \\
(-0.058)\end{array}$ & $\begin{array}{c}0.009 \\
(1.127)\end{array}$ & $\begin{array}{c}\mathbf{0 . 6 8 4} \\
(10.062)\end{array}$ & $\begin{array}{c}-0.004 \\
(-1.201)\end{array}$ & $\begin{array}{c}-0.006 \\
(-1.839)\end{array}$ & & 0.52 \\
\hline$d_{t+1}-p_{t+1}$ & $\begin{array}{c}-0.007 \\
(-1.491)\end{array}$ & $\begin{array}{l}-0.102 \\
(-1.535)\end{array}$ & $\begin{array}{l}\mathbf{1 . 3 4 7} \\
(2.784)\end{array}$ & $\begin{array}{c}\mathbf{0 . 9 7 2} \\
(40.597)\end{array}$ & $\begin{array}{c}-0.038 \\
(-1.080)\end{array}$ & & 0.94 \\
\hline$d_{t+1}-e_{t+1}$ & $\begin{array}{c}-0.001 \\
(-0.119)\end{array}$ & $\begin{array}{l}-0.142 \\
(-1.067)\end{array}$ & $\begin{array}{l}\mathbf{- 2 . 4 9 9} \\
(-2.191)\end{array}$ & $\begin{array}{c}0.012 \\
(0.356)\end{array}$ & $\begin{array}{c}\mathbf{0 . 6 4 4} \\
(8.273)\end{array}$ & & 0.50 \\
\hline$H$ & 2 & 3 & 4 & 8 & 12 & 16 & 24 \\
\hline Implied $R^{2}$ & 0.13 & 0.15 & 0.17 & 0.23 & 0.28 & 0.32 & 0.39 \\
\hline Dependent Variable & $\begin{array}{l}\text { Constant } \\
(t \text {-stat })\end{array}$ & $\begin{array}{c}r_{t}-r_{f, t} \\
(t \text {-stat })\end{array}$ & $\begin{array}{l}R R E L_{t} \\
(t \text {-stat })\end{array}$ & $\begin{array}{l}d_{t}-p_{t} \\
(t \text {-stat })\end{array}$ & $\begin{array}{l}d_{t}-e_{t} \\
(t \text {-stat })\end{array}$ & $\begin{array}{c}\widehat{c a y}_{t} \\
(t \text {-stat })\end{array}$ & $\overline{\overline{R^{2}}}$ \\
\hline$r_{t+1}-r_{f, t+1}$ & $\begin{array}{c}-0.000 \\
(-0.028)\end{array}$ & $\begin{array}{c}-0.008 \\
(-0.126)\end{array}$ & $\begin{array}{l}\mathbf{- 1 . 1 8 1} \\
(-2.600)\end{array}$ & $\begin{array}{c}-0.003 \\
(-0.101)\end{array}$ & $\begin{array}{c}0.016 \\
(0.451)\end{array}$ & $\begin{array}{c}\mathbf{1 . 9 0 8} \\
(3.316)\end{array}$ & 0.11 \\
\hline$R R E L_{t+1}$ & $\begin{array}{c}-0.000 \\
(-0.037)\end{array}$ & $\begin{array}{c}0.012 \\
(1.515)\end{array}$ & $\begin{array}{c}\mathbf{0 . 6 7 9} \\
(9.435)\end{array}$ & $\begin{array}{c}-0.002 \\
(-0.620)\end{array}$ & $\begin{array}{c}-0.005 \\
(-1.790)\end{array}$ & $\begin{array}{c}-0.072 \\
(-0.952)\end{array}$ & 0.52 \\
\hline$d_{t+1}-p_{t+1}$ & $\begin{array}{c}-0.007 \\
(-1.458)\end{array}$ & $\begin{array}{c}-0.047 \\
(-0.698)\end{array}$ & $\begin{array}{l}\mathbf{1 . 2 6 4} \\
(2.687)\end{array}$ & $\begin{array}{c}\mathbf{0 . 9 9 5} \\
(39.723)\end{array}$ & $\begin{array}{c}-0.032 \\
(-0.913)\end{array}$ & $\begin{array}{l}\mathbf{- 1 . 2 3 5} \\
(-2.358)\end{array}$ & 0.94 \\
\hline$d_{t+1}-e_{t+1}$ & $\begin{array}{c}-0.001 \\
(-0.127)\end{array}$ & $\begin{array}{c}-0.162 \\
(-1.057)\end{array}$ & $\begin{array}{l}\mathbf{- 2 . 4 6 9} \\
(-2.184)\end{array}$ & $\begin{array}{c}0.004 \\
(0.091)\end{array}$ & $\begin{array}{c}\mathbf{0 . 6 4 2} \\
(8.178)\end{array}$ & $\begin{array}{c}0.441 \\
(0.411)\end{array}$ & 0.50 \\
\hline$\widehat{c a y}_{t+1}$ & $\begin{array}{c}-0.000 \\
(-0.303)\end{array}$ & $\begin{array}{l}\mathbf{- 0 . 0 4 9} \\
(-8.235)\end{array}$ & $\begin{array}{c}-0.062 \\
(-1.499)\end{array}$ & $\begin{array}{c}\mathbf{0 . 0 0 4} \\
(2.858)\end{array}$ & $\begin{array}{c}0.001 \\
(0.331)\end{array}$ & $\begin{array}{c}\mathbf{0 . 8 6 2} \\
(21.854)\end{array}$ & 0.78 \\
\hline$H$ & 2 & 3 & 4 & 8 & 12 & 16 & 24 \\
\hline Implied $R^{2}$ & 0.22 & 0.30 & 0.30 & 0.35 & 0.38 & 0.40 & 0.44 \\
\hline
\end{tabular}


Notes for Table 6: Sample period is 1952:4 - 1998:3, OLS estimation. Coefficients from vector autoregressions (VARs) of returns, relative bill rate, dividend yield, dividend payout ratio and the trend deviation term. $r_{t+1}-r_{f, t+1}$, is quarterly log excess returns on the S\&P Composite index; $R R E L_{t}$ is the relative bill rate; $d_{t}-p_{t}$ is the log dividend yield; $d_{t}-e_{t}$ is the log dividend payout ratio; $\widehat{c a y}_{t}$ is $c_{t}-\widehat{\beta}_{a} a_{t}-\widehat{\beta}_{y} y_{t}$, the estimated trend deviation. Newey-West corrected t-statistics appear in parentheses below the coefficient estimate. Significant coefficients at the $5 \%$ level are highlighted in bold. $H$ denotes the return horizon in quarters. The row labeled "Implied $R$ " gives the explanatory power of the VAR for the return at horizon $H$ named in the row above and is calculated from the estimated parameters of the VAR and the estimated covariance matrix of VAR residuals. 


\section{Table 7}

Out-of-sample Predictive Power of $\widehat{\text { aay }_{t}}$ in One-Quarter-Ahead Forecasts of Excess Returns

\begin{tabular}{ccccc}
\hline \hline \multicolumn{5}{c}{ Cointegrating Vector Reestimated } \\
Row & Lag of trend-deviation & $M S E_{u} / M S E_{r}$ & CM Test Statistic & OOS $F$-Test Statistic \\
\hline 1 & $\widehat{c a y}_{t}$ & 0.955 & $9.15^{* *}$ & $5.72^{* *}$ \\
2 & $\widehat{c a y}_{t-1}$ & 0.985 & $4.02^{* *}$ & $1.85^{*}$ \\
\hline & & Fixed Cointegrating Vector & \\
Row & Lag of trend-deviation & $M S E_{u} / M S E_{r}$ & CM Test Statistic & OOS F-Test Statistic \\
\hline 3 & $\widehat{c a y}_{t}$ & 0.925 & $12.93^{* *}$ & $9.84^{* *}$ \\
4 & $\widehat{c a y}_{t-1}$ & 0.955 & $6.58^{* *}$ & $5.72^{* *}$ \\
\hline \hline
\end{tabular}

Notes for Table 7: One-step ahead forecasts of excess returns on the S\&P Composite Index, $r_{t+1}-$

$r_{f, t+1} . \widehat{c a y}_{t}$ is $c_{t}-\widehat{\beta}_{a} a_{t}-\widehat{\beta}_{y} y_{t}$, the estimated one-period lagged trend deviation. In rows 1 and 3 , $M S E_{u}$ is the mean-squared forecasting error from a model which includes the one-period lagged dependent variable $r_{t}-r_{f, t}$, and the one-period lagged value of $\widehat{c a y}_{t}$ as explanatory variables; rows 2 and 4 replace the one-period lagged value, $\widehat{c a y}_{t}$, with the two period lagged value, $\widehat{c a y}_{t-1} \cdot M S E_{r}$ is the mean-squared error from the model using only the lagged dependent variable. The column labeled "CM Test Statistic" gives the modified Harvey, Leybourne, and Newbold test statistic (Clark and McCracken 1999). The column labeled "OOS F-Test Statistic" gives the out-of-sample $F$-test statistic (McCracken 1999). The initial estimation period begins with the fourth quarter of 1954 and ends with the first quarter of 1968. The model is recursively reestimated until the third quarter of 1998 .

*Significant at the 5 percent or better level.

**Significant at the 1 percent or better level. 


\section{Table A.1}

\section{Dickey-Fuller Tests for Unit Roots}

\begin{tabular}{c|c|c|c|c|c|c}
\hline \hline & \multicolumn{3}{|c|}{ Dickey-Fuller $t$-statistic } & \multicolumn{3}{c}{ Critical Values } \\
\hline & Lag=1 & Lag=2 & Lag=3 & Lag=4 & $5 \%$ Critical Level & 10\% Critical Level \\
\hline $\log$ (Wealth) & -2.088 & -2.763 & -2.607 & -2.926 & 3.44 & 3.14 \\
$\log ($ Labor Income) & -0.760 & -0.920 & -0.944 & -0.919 & 3.44 & 3.14 \\
$\log ($ Consumption $)$ & -0.734 & -1.120 & -1.246 & -1.578 & 3.44 & 3.14 \\
\hline \hline
\end{tabular}

Notes: Sample is 1953:1 to 1998:3. All variables are real, in per-capita terms. Model includes a time trend.

\section{Table A.2}

Phillips-Ouliaris Test for Cointegration

\begin{tabular}{cccc|c|c}
\hline \hline \multicolumn{3}{c|}{ Dickey-Fuller $t$-statistic } & \multicolumn{3}{c}{ Critical Values } \\
\hline $\mathrm{Lag}=1$ & $\mathrm{Lag}=2$ & $\mathrm{Lag}=3$ & $\mathrm{Lag}=4$ & $5 \%$ Critical Level & $10 \%$ Critical Level \\
\hline-4.282 & -4.017 & -3.800 & -3.636 & -3.80 & -3.52 \\
\hline \hline
\end{tabular}

Notes: See Table A.1. Dickey-Fuller test statistic has been applied to the fitted residuals from the cointegrating regression of consumption on labor income and wealth. Critical values assume trending series. "Lags" refers to the number of lags of first differences used in the regression of residuals on the lagged residual and lags of first differences of the residual. 
Table A.3

Johansen Cointegration Test: I(1) Analysis With Linear Trend in the Data

\begin{tabular}{|c|c|c|c|c|}
\hline \multicolumn{5}{|c|}{ Lag in VAR Model= 1} \\
\hline \multicolumn{2}{|c|}{ L-Max } & \multicolumn{2}{|c|}{ Trace } & \multirow{2}{*}{$\begin{array}{c}H_{o}=r \\
r=\end{array}$} \\
\hline Test Statistic & $90 \% \mathrm{CV}$ & Test Statistic & $90 \% \mathrm{CV}$ & \\
\hline 19.49 & 13.39 & 24.85 & 26.70 & 0 \\
\hline 5.28 & 10.60 & 5.36 & 13.31 & 1 \\
\hline 0.08 & 2.71 & 0.08 & 2.71 & 2 \\
\hline \multicolumn{5}{|c|}{ Lag in VAR Model $=2$} \\
\hline \multicolumn{2}{|c|}{ L-Max } & \multicolumn{2}{|c|}{ Trace } & $H_{o}=r$ \\
\hline Test Statistic & $90 \% \mathrm{CV}$ & Test Statistic & $90 \% \mathrm{CV}$ & $r=$ \\
\hline 21.03 & 13.39 & 25.17 & 26.70 & 0 \\
\hline 4.05 & 10.60 & 4.14 & 13.31 & 1 \\
\hline 0.10 & 2.71 & 0.10 & 2.71 & 2 \\
\hline \multicolumn{5}{|c|}{ Lag in VAR Model $=3$} \\
\hline \multicolumn{2}{|c|}{ L-Max } & \multicolumn{2}{|c|}{ Trace } & $H_{o}=r$ \\
\hline Test Statistic & $90 \% \mathrm{CV}$ & Test Statistic & $90 \% \mathrm{CV}$ & $r=$ \\
\hline 16.01 & 13.39 & 20.08 & 26.70 & 0 \\
\hline 4.00 & 10.60 & 4.08 & 13.31 & 1 \\
\hline 0.08 & 2.71 & 0.08 & 2.71 & 2 \\
\hline \multicolumn{5}{|c|}{ Lag in VAR Model $=4$} \\
\hline \multicolumn{2}{|c|}{ L-Max } & \multicolumn{2}{|c|}{ Trace } & $H_{o}=r$ \\
\hline Test Statistic & $90 \% \mathrm{CV}$ & Test Statistic & $90 \% \mathrm{CV}$ & $r=$ \\
\hline 14.80 & 13.39 & 19.17 & 26.70 & 0 \\
\hline 4.09 & 10.60 & 4.37 & 13.31 & 1 \\
\hline 0.27 & 2.71 & 0.27 & 2.71 & 2 \\
\hline
\end{tabular}

Notes: See Table A.1. Constant included in cointegrating relation. The columns labeled "Test Statistic" give the value for the test named in the row above; "90\% CV" gives the 90 percent 
confidence level of that statistic. 
Figure 1

Excess Return and Trend Deviation 1952:4 to $1998: 3$

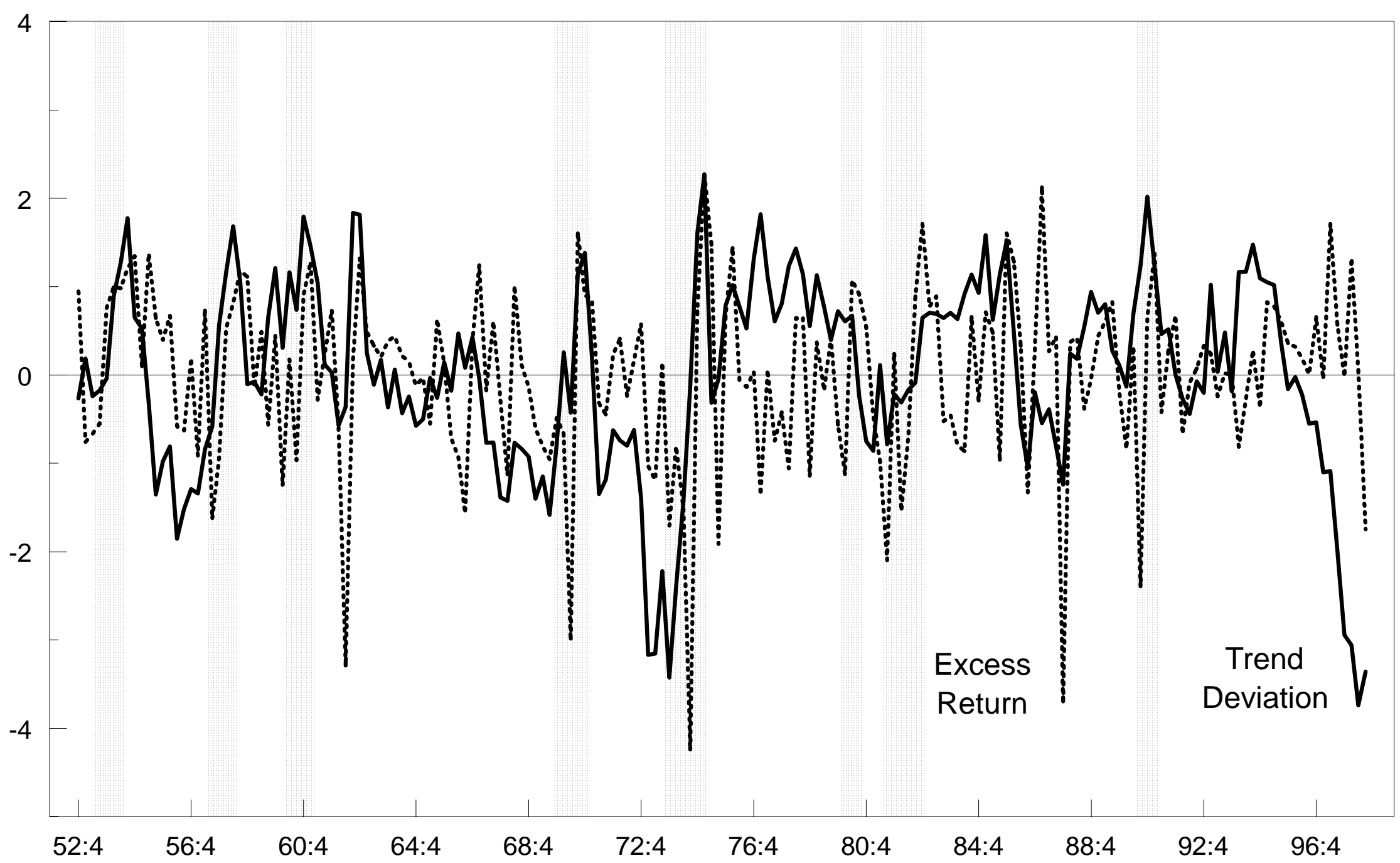

Notes: Excess return is the return on the S\&P Composite Index less the return on the three month Treasury bill rate; Trend deviation is the estimated deviation from the shared trend in consumption, labor income and asset wealth (normalized to standard deviations of unity). Shaded areas denote recessions. 